\title{
Espacio y tiempo en la Edad del Bronce del País Valenciano
}

\author{
Mauro S. Hernández Pérez*
}

\begin{abstract}
RESUMEN ABSTRACT
Se realizan algunas consideraciones sobre el origen, cronología y periodización de la Edad del Bronce en el País Valenciano (España) a partir de las dataciones absolutas publicadas, analizándose los contextos arqueológicos de cada una de ellas.

Some considerations are made on the origin, chronology and periodization of the Bronze Age in País Valenciano (Spain) from the absolute datings already published, analyzins their respective archaeological contexts.
\end{abstract}

\section{PALABRAS CLAVE}

Edad del Bronce. Bronce Agárico. Bronce Valenciano. Bronce Tardío. País Valenciano.

Hace 35 años se consideraba la Edad del Bronce como «uno de los núcleos prerromanos más importantes de las tierras valencianas que por otra parte presenta un considerable interés dada la homogeneidad de sus características tanto en lo que se refiere a situación y aspecto como a los hallazgos» (Tarradell, 1963: 130). El tiempo transcurrido ha acrecentado este interés, del que es fiel reflejo el significativo número de proyectos de investigaciones y de excavaciones aisladas que se programan, y en ocasiones hasta se realizan, desde los centros universitarios, servicios de Arqueología y museos provinciales y municipales. Lamentablemente este interés no se acompaña $-y$ de ello todos somos culpables, el primero yo mismo-, de la publicación de sus resultados por lo que retomando también sus propias palabras «caeríamos

\footnotetext{
* Universidad de Alicante.
} 
en un error si supusiéramos que se trata de un período bien conocido» (Tarradell, 1963: 130).

No pretendemos realizar una nueva síntesis sobre la Edad del Bronce, ya que poco se puede añadir a las elaboradas en los últimos años. Nos detendremos, en cambio, en algunas cuestiones relacionadas con su origen, cronología y periodización, al tiempo que se destacan los avances más significativos de la investigación y las cuestiones pendientes en el estudio de una etapa de la Prehistoria que durante más de un milenio se extiende por un territorio alargado, en contacto con el sudeste, noreste e interior peninsular, bañado por un mar de cultura e intercambios, con cadenas montañosas y valles de ríos que permiten una no siempre fácil comunicación entre sus tierras y de éstas con las limítrofes. Espacio y Tiempo serán, por tanto, conceptos siempre presentes, sin olvidar el de la Forma, aquí entendida como los elementos culturales que dan contenido a los dos anteriores.

\section{BRONCE ARGÁRICO-BRONCE VALENCIANO-BRONCE EN EL PAÍS VALENCIANO}

En los últimos tiempos se ha generalizado en la bibliografía arqueológica valenciana la denominación genérica de Edad del Bronce ante las dificultades para definir el llamado Bronce Valenciano, una de las culturas que desde los estudios de M. Tarradell se asocia con estas tierras, mientras la otra - la argárica - es mejor conocida, al menos en su área nuclear. En principio puede parecer una cuestión secundaria la utilización del término Edad del Bronce en el (o del) País Valenciano, aunque en nuestra opinión es fiel reflejo del estado actual de la investigación que incide en la definición del Bronce Valenciano, de las características del Bronce Argárico en estas tierras y del controvertido tema de las fronteras entre ambas y con las tierras y culturas del Bajo Aragón y CastillaLa Mancha. Por todo elio, consideramos conveniente detenernos en primer lugar, aunque no con la extensión y profundidad requerida, en estos temas.

Es incuestionable la presencia argárica en las tierras valencianas (Hernández Pérez, 1986 y 1997; Soriano, 1984). Lamentablemente carecemos de un análisis riguroso sobre sus características, cronología y distribución territorial. Prácticamente todos los investigadores coinciden en la consideración de argáricos para los yacimientos de San Antón de Orihuela y Las Laderas del Castillo de Callosa del Segura, descubiertos y excavados por J. Furgús a principios de siglo (Furgús, 1937), aunque el primero 
ya era conocido por S. Moreno Tovillas (1942), los hermanos Siret (1890: 308) y T. Brotons (Nieto Gallo, 1959), no realizándose excavaciones con posterioridad, mientras en el segundo excavaría J. Colominas (1925, 1927 y 1931). Fue E. Siret quien primero relacionó San Antón con El Argar al indicar que las excavaciones en este yacimiento «en fournissent un nouveau et intéressant témoignage, par il s'agit bien du même peuple» (Siret, 1905: 380), consideración que fija definitivamente M. Tarradell (1963 y 1969) y corroboraría más tarde $V$. Lull en su síntesis sobre esta cultura (Lull, 1983: 336-341). No obstante, la información sobre estos yacimientos de la Vega Baja del Segura se encuentra lastrada por los trabajos de campo -el propio Furgús no llegó a identificar el poblado sobre las tumbas, a pesar de que previamente a sus trabajos se había indicado la existencia de un posible poblado (Siret, 1890: 308) -, la parcialidad y confusión en la publicación de sus resultados y los avatares que han sufrido los materiales arqueológicos, dispersos los de San Antón entre el Museo Arqueológico Provincial de Alicante, donde se encuentra depositada la colección del Colegio de la Inmaculada heredera de aquella antigua del Colegio de Santo Domingo de Orihuela (Rubio de la Serna, 1907), y el Museo Arqueológico Comarcal de Orihuela, mientras los materiales de las excavaciones de J. Corominas en Las Laderas fueron depositados en el Museo Arqueológico de Barcelona y los hallados con posterioridad en el Museo Municipal de Callosa del Segura (Soriano Sánchez, 1989). La revisión de estas colecciones (Soriano Sánchez, 1984 y 1985) revela la larga ocupación de ambos yacimientos, sin que se pueda precisar si es continua y el momento inicial de ésta, evidentemente en el Bronce Antiguo.

Sobre los restantes yacimientos de la Vega Baja y el Bajo Vinalopó la información disponible se reduce a unos escasos y pocos significativos objetos metálicos y unas cerámicas cuya identificación como argáricas resulta, cuando menos aventurada, si exceptuamos el conjunto de Caramoro, en Elche, con tres copas (Ramos Fernández, 1988; González Prats y Ruiz Segura, 1995), el pie de copa de la Serra del Búho IV, en Elche (Román Lajarín, 1980), la forma 6 de Siret junto a vasos de carena media del Pic de les Moreres (González Prats, 1986 a: 125), además del conjunto cerámico inédito de San Isidro de Albatera.

También se constata una presencia argárica antigua en el Tabayá, en Aspe (Hernández Pérez, 1990), un poblado que perdura hasta el Bronce Final (Hernández Pérez y López Mira, 1992), mientras en la llleta dels Banyets, en El Campello (Simón García, 1997), tras su ocupación inicial en el Bronce Antiguo se abandona en el Bronce Medio para ocuparse de nuevo en el Bronce Tardío. 
La definición de Bronce Valenciano corresponde a M. Tarradell, si bien con anterioridad otros investigadores habían llamado la atención sobre las especiales características de los poblados y de sus materiales. Sin embargo, el mismo título del artículo - Dos estaciones argáricas en la Región Levantina- que da cuenta de los hallazgos en La Atalayuela, en Losa del Obispo, refleja las ideas del momento (Alcácer Grau, 1945) acerca de la amplia distribución de El Argar. A partir de las primeras propuestas de M. Tarradell sobre la Edad del Bronce peninsular (Tarradell, 1947 y 1950) se comienza a identificar al norte del Segura, hasta el que todos hacen llegar el Argar para incluir los yacimientos de Orihuela y Callosa, un Bronce con características propias - Bronce levantino (Flecher, 1953) o Bronce Pleno (Pla, 1958)-, en el que siempre se indican influencias argáricas. Para M. Tarradell el término de cultura de Bronce Valenciano «no significa solamente que los yacimientos y materiales pertenecen a la Edad del Bronce, sino que además le concedemos un claro valor de unidad cultural». Los elementos que permitían diferenciarlo del Bronce Argárico eran la ausencia de enterramientos bajo las casas, la escasez de utillaje metálico y la ausencia de algunas formas cerámicas características de este último, como las copas, o la escasa presencia de recipientes carenados. Durante mucho tiempo el Bronce Valenciano era «la cultura del no», de la ausencia de "lo argárico». Esta visión ha cambiado y en la actualidad «el Bronce Valenciano se caracteriza por la ubicación de los poblados en alturas de difícil acceso, amurallados en sus partes accesibles y completados los recintos con torres; las casas, con zócalo de piedra y paredes más endebles, serán de planta cuadrada o rectangular; los enterramientos individuales 0 de pocos individuos en covachos y grietas próximas a los lugares de habitación; la cultura material es parca en útiles de sílex, si exceptuamos los dientes de hoz, e incluye algunas hachas de piedra pulimentada, brazaletes de arquero, punzones de hueso y útiles de cobre o bronce como los puñales de remaches, hachas planas y punzones. La cerámica, siempre el elemento más abundante, presenta pastas poco depuradas y baja temperatura de cocción; escasa decoración que se reduce, en general, a cordones aplicados y algunas incisiones, y corta variación de sus formas» (Martí y Bernabeu, 1992: 556).

Fue también $\mathrm{M}$. Tarradell quien estableció por vez primera la existencia de facies en el Bronce Valenciano al señalar que «buscando posibilidades de subdivisiones cronológicas, lo que más bien nos parece hallar es una diferenciación geográfica» (Tarradell, 1969: 26) que se refleja en las formas y decoraciones cerámicas, fijando la existencia de dos zonas con una frontera en el Júcar-Túria. Estos argumentos se repiten en las síntesis posteriores, hasta que por nuestra parte propusi- 
mos la existencia de «facies comarcales, cuyo origen debe buscarse en sustratos e influencias diferentes en cada zona y en una adaptación al medio por parte de las comunidades humanas" (Hernández Pérez, 1985: 116), distinguiendo una de ellas en el Vinalopó (Hernández Pérez, 1986: 348 ), en el que a menudo se sitúan las fronteras entre los bronces Argárico y Valenciano, y con posterioridad otra en el interior montañoso de la actual provincia de Alicante (Hernández Pérez, 1997). También F. Gusi ha insistido en estas facies al señalar que «cada comunidad o grupo social perteneciente al Bronce Valenciano, hubo de poseer rasgos materiales de funcionamiento propio como corresponderia a formaciones socio-económicas distintas; y por tanto, inferimos numerosas diferenciaciones, no sólo en las industrias y utillajes de su cultura material, sino también en otros aspectos estructurales básicos» (Gusi Jener, 1989: 244-245).

Teniendo en cuenta la existencia en las actuales tierras valencianas de yacimientos argáricos y de otros que podrían pertenecer al Bronce Valenciano si se admitiese en éste facies comarcales, todavía no bien definidas, optamos hace ya algún tiempo (Hernández Pérez, 1985) por utilizar la denominación de Edad del Bronce para referirnos a las poblaciones del II milenio arq. ANE a la espera de la refinición del Bronce Valenciano, término que ha encontrado fortuna en las síntesis posteriores (De Pedro Michó, 1995; Gusi Jener, 1989; Martí y Bernabeu, 1992).

\section{CRONOLOGÍA Y PERIODIZACIÓN}

Señalaba hace 35 años $M$. Tarradell que la cronología y periodización del Bronce Valenciano era «de momento muy incierta y aventurada» (Tarradell, 1963: 175), para indicar años más tarde que «estamos ante una civilización que tendió al estancamiento, que no se renovó, que vivió durante siglos bajo módulos parecidos» (Tarradell, 1969: 26), lo que se reflejaba en la monotonía de sus materiales y la lentitud de su evolución.

M.Tarradell mantenía la perduración de este Bronce Valenciano hasta la iberización. Las excavaciones de los años 70 en los poblados de Vinarragell y Saladares aportaron nueva información sobre los momentos finales de la Edad del Bronce -objeto de un reciente análisis al que remitimos (Martí Oliver y De Pedro Michó, 1997) - , que concluyeron en los inicios de la década siguiente con la propuesta de identificación de un Bronce Tardio y un Bronce Final (Gil-Mascarell, 1991), según el modelo propuesto para el Sudeste (Molina, 1978). También el «modelo su- 
deste", en este caso argárico, y una serie cada vez más numerosa de dataciones absolutas han sido los criterios utilizados para establecer una periodización de los momentos anteriores a este Bronce Tardío, por otro lado recientemente cuestionado (Delibes de Castro y Abarquero Moras, 1997).

Primero R. Enguix (1980: 169-170) y luego J.F. Navarro Mederos (1982: 66-67) proponen una periodización del Bronce Valenciano en tres fases - Antiguo, Medio y Final (R. Enguix) o Antiguo, Avanzado y Tardío (J.F. Navarro)-, a partir del análisis de materiales procedentes de excavaciones antiguas, recogidas superficiales y de actuaciones clandestinas. Esta división tripartita del Bronce Valenciano es mantenida por M.GilMascarell y R. Enguix (1986), asociando al Bronce Pleno, que sitúan entre el 1.600-1.200 arq. ANE, los elementos culturales tradicionalmente considerados del Bronce Valenciano. En este sentido conviene recordar las propuestas que excluyen el Bronce Tardío y Final del Bronce Valenciano, al tiempo que éste se convierte en «sinónimo de Bronce Pleno. Y habrá que discutir si también será sinónimo de Bronce Antiguo" (Martí y Bernabeu, 1992: 558), opinión que se mantiene en la más reciente síntesis (De Pedro Michó, 1995: 65).

Por su parte, F. Gusi Jener proponía en 1975, además de la existencia de facies de las que ya hemos hecho mención, una periodización del Bronce Valenciano en cuatro fases sobre la base de las dataciones absolutas conocidas en ese momento, presuponiendo que dada su fuerte homogeneidad «su periodización ni podía ser excesivamente corta, ni demasiada larga" (Gusi Jener, 1975: 77), con una media de 250-300 años para cada una de ellas. El Bronce Valenciano I, que abarca del 1900/1850 al 1600/1550, estaría representado en Serra Grossa, Terlinques, la fase II de Cabezo Redondo, Pic dels Corbs y Catí Foradà, al Bronce Medio, con una cronología del 1550/1500 al 1250/1200, se asocia el nivel II de Mas d'Abad, la fase I del Cabezo Redondo y los niveles II y III del Torrelló, mientras para el Bronce Valenciano III, datado entre el 1200/1150 y $900 / 850$, y el Bronce Valenciano IV, con una cronología del 850/800$750 / 600$, sólo adscribe un yacimiento a cada uno -el nivel I de Mas d'Abad y Vinarragell, respecticamente-.

El mismo investigador, ahora con $\mathrm{C}$. Olaria, retoma la periodización de la Edad del Bronce en el País Valenciano al publicar las fechas absolutas conocidas en 1993 agrupándolas en la tradicional división tripartita de los períodos prehistóricos. En el Bronce Antiguo incluyen 15 dataciones, obtenidas de los yacimientos de Cabezo Redondo, Mas del Corral, Serra Grossa, Terlinques, Lloma de Betxí, Pics dels Corbs, Orpesa la 
Vella y Forat de Cantallops, que abarcan del 1.874 al 1.556 ANE $-2.919 / 1.835$ cal ANE-. Para el Bronce Medio disponen de 14 dataciones de los yacimientos de Cabezo Redondo, Catí Foradà, Lloma Redona, Orpesa la Vella, Cova del Mas d'Abad, Abric de Can Ballester, El Torrelló y Cueva del Murciélago, que ofrecen una cronología del 1.640 al 1.273 ANE -1.914 al 1.497 cal. ANE-. Para el Bronce Final sólo recogen 8 dataciones de los yacimientos de Peña Negra, Orpesa la Vella, Cova de Mas d'Abad, Abric de Les Cinc, Cueva del Murciélago y Torrelló del Boverot que permiten situar esta fase entre el 1.049 al 736 ANE -1.203 al 864 cal. ANE-.

$Y$ de nuevo, nos remontamos a hace 35 años cuando $M$. Tarradell al concluir su análisis de la Edad del Bronce en el País Valenciano, señalaba que "caeríamos en un error si supusiéramos que se trata de un período bien conocido (Tarradell, 1963: 130), abogando por «la aplicación del C.14 a materiales procedentes de los yacimientos señalados, en las diversas áreas, que podrá darnos un día una base de cronología absoluta que ahora no se tiene, y sólo con un elemento de este tipo, o con series estratigráficas que permitan una estratigrafía comparada, será posible organizar una teoría montada sobre terreno seguro" (Tarradell, 1963: 180). 35 años después disponemos de un considerable número de dataciones absolutas y excavaciones recientes en todo el territorio valenciano y, sin embargo, ahora como entonces se debe insistir en que hay que esperar más documentación y que todavía no es posible organizar una teoría montada sobre terreno seguro. En efecto, disponemos en la actualidad de un significativo número de dataciones absolutas pero carecemos de series estratigráficas publicadas, que existen y algunas de ellas abarcando toda la secuencia. No obstante, carecemos de modelos y propuestas que organicen una información cada día más abundante.

Las dataciones absolutas son necesarias y urgentes. Su valor, en cambio, será relativo y en ocasiones nulo si se desconoce lo que se va a datar y si su publicación no es acompañacia por la información complementaria sobre el origen y situación de la muestra y, en especial, de los contextos arqueológicos con los que se asocia. Las dataciones absolutas para la Edad del Bronce en el País Valenciano reflejan con claridad algunas de las cuestiones, por lo que, tras recopilar las dataciones publicadas (Castro Martínez, Lull y Mico, 1996; Gusi y Olaria, 1995), realizaremos una valoración de cada una de ellas.

De estas relaciones la más completa es la recogida por $F$. Gusi y $C$. Olaria con ocasión de la Jornadas de Arqueología Valenciana de 1993. Las diferencias entre unas mismas dataciones calibradas se explican por 
la utilización de distintas versiones del programa CALIB 3 de Stuiber y Reiner, correspondiendo la de F. Gusi y C. Olaria a la versión 3.0.3. En la relación adjunta que constituye la figura 1 la columna de la Datación media calibrada ANE la primera cifra corresponde a la publicada por estos dos investigadores, mientras la segunda acompañada por un asterisco es la proporcionada P.V. Castro, V. Lull y R. Micó y el doble asterisco entre paréntesis señala las dataciones que los mismos investigadores descartan por proceder del Laboratorio de Gakushuin (Tokio, Japón) —la del Pic de les Moreres y dos de Peña Negra-o por desviación tipo muy elevada - una de El Torrelló-.

Disponemos, por tanto, de 43 dataciones publicadas. Sin embargo, su valor es desigual ya que de muchas desconemos los contextos, de otras éstos reflejan, según los materiales arqueológicos publicados, evidentes confusiones y algunas de ellas son, cuando menos, poco fiables por el tipo de muestra, el proceso de recogida y manipulación posterior o por el Laboratorio donde se ha realizado el análisis.

La datación más antigua corresponde al yacimiento crevillentino de Pic de les Moreres y se considera elevada - 2.558 cal ANE m- para un poblado relacionado con el Argar A (González Prats, 1983: 266). El tipo de muestra - hueso- y el laboratorio - Gakushuin- aconsejan descartar esta datación (Castro Martínez, Lull y Micó, 1996: 136), explicándose así su desfase con los materiales que se relacionan con el Argar A o con el Horizonte Campaniforme de Transición (González Prats, 1983: 266).

En la provincia de Castellón se encuentra la otra datación más elevada para la Edad del Bronce -2.290 cal ANE m.-, correspondiendo al Forat de Cantallops. Se trata de una alargada cueva en las que se excavaron $47 \mathrm{~m}^{2}$, repartidos en 16 cortes de unos 0 '30 $\mathrm{m}$ de potencia, con la excepción del sondeo en el vestíbulo que alcanzó los 1'30 m. La datación procede de carbones del nivel 1 de los cuadros 3 bis y 4 bis «que el laboratorio mezcló para compensar la escasez de la muestra dado que ambas se presentaban en el mismo nivel» (Olaria, 1977: 278-279). De estos cortes sólo se han publicado 4 fragmentos cerámicos (figura 2), uno perteneciente a una vasija carenada y otro con decoración de cordones. Para sus excavadores se trata de una cueva sólo «habitada en época temporal o estacional», explicando la presencia de las puntas de flecha de sílex como «un utillaje arcaizante que hubiese perdurado con mayor intensidad en la zona interior montañosa" (Olaria y Gusi, 1976: 147). Esta ocupación esporádica de la cueva, de problemática datación absoluta, se refleja en la diversidad de sus materiales cerámicos difícilmente coetáneos entre sí y con el utillaje óseo. 
Espacio y tiempo en la Edad del Bronce del País Valenciano

\begin{tabular}{|c|c|c|c|c|c|c|c|}
\hline $\begin{array}{l}\text { Yacimiento } \\
\text { (provincia) }\end{array}$ & $\begin{array}{l}\text { Labora- } \\
\text { torio }\end{array}$ & Muestra & $\begin{array}{l}\text { Datación } \\
\text { BP }\end{array}$ & $\begin{array}{l}\text { Datación } \\
\text { ANE. }\end{array}$ & $\begin{array}{c}\text { Datación } \\
\text { cal BP }\end{array}$ & $\begin{array}{l}\text { Datación } \\
\text { Cal ANE }\end{array}$ & $\begin{array}{c}\text { Datación } \\
\text { cal ANE m }\end{array}$ \\
\hline Pic de les Moreres (A) & Gak-9775 & hueso & $4.070 \pm 140$ & $2.120 \pm 140$ & $4.869-4.147$ & $2.919-2.197$ & $2.558-\left({ }^{*}\right)$ \\
\hline Forat de Cantallops (C) & $\mathrm{CSIC} / 346$ & carbón & $3.830 \pm 70$ & $1.880 \pm 70$ & $4.414-4.067$ & $2.464-2.117$ & 2.290 \\
\hline Serra Grossa $(A)$ & $\mathrm{BLN}-947$ & cereal & $3.815 \pm 100$ & $1.865 \pm 100$ & $4.443-3.900$ & $2.493-1.956$ & $2.224-2.310\left(^{*}\right)$ \\
\hline Terlinques (A) & 1.4525 & carbón & $3.880 \pm 100$ & $1.850 \pm 100$ & $4.448-3.856$ & $2.498-1.906$ & $2.202-2.270\left(^{*}\right)$ \\
\hline Mas del Corral $(A)$ & AA-6146 & carbón & $3.770 \pm 60$ & $1.820 \pm 60$ & $4.305-3.965$ & $2.335-2.015$ & 2.175 \\
\hline Lloma de Betxí (V) & Ly-5053 & carbón & $3.725 \pm 60$ & $1.775 \pm 60$ & $4.239-3.886$ & $2.289-1.963$ & $2.126-2.137\left(^{\star}\right)$ \\
\hline Orpesa la Veila (C) & $\mid-15843$ & carbón & $3.720 \pm 100$ & $1.770 \pm 100$ & $4.357-3.827$ & $2.407-1.877$ & 2.142 \\
\hline Orpesa la Veila (C) & $\mid-15861$ & carbón & $3.710 \pm 100$ & $1.760 \pm 100$ & $4.352-3.824$ & $2.402-1.874$ & 2.138 \\
\hline Mas del Corral (A) & AA-7320 & carbón & $3.710 \pm 65$ & $1.760 \pm 65$ & $4.235-3.860$ & $2.285-1.910$ & 2.097 \\
\hline Orpesa la Veila (C) & 1.13010 & carbón & $3.700 \pm 130$ & $1.750 \pm 130$ & $4.360-3.706$ & $2.410-1.756$ & 2.083 \\
\hline Lloma de Betxi (V) & Ly-5054 & carbón & $3.645 \pm 65$ & $1.695 \pm 65$ & $4.097-3.823$ & $2.147-1.873$ & $\left.2.010-2.032()^{*}\right)$ \\
\hline Lloma de Betxi (V) & Ly- 5052 & carbón & $3.565 \pm 55$ & $1.615 \pm 55$ & $3.084-3.963$ & $2.034-1.743$ & $1.888-1.919\left({ }^{\circ}\right)$ \\
\hline Lloma de Betxi (V) & Ly.5055 & carbón & $3.565 \pm 55$ & $1.555 \pm 55$ & $3.896-3.632$ & $1.946-1.682$ & $1.814-1.834\left(4^{*}\right)$ \\
\hline Orpesa la Vella $(\mathrm{C})$ & $1-16137$ & carbón & $3.550 \pm 100$ & $1.600 \pm 100$ & $4.091-3.572$ & $2.141-1.622$ & 1.881 \\
\hline Orpesa la Vella (C) & $\mid-13014$ & carbón & $3.500 \pm 90$ & $1.600 \pm 90$ & $4.086-3.622$ & $2.136-1.672$ & 1.904 \\
\hline Cabezo Redondo (A) & $\mathrm{H}-2277$ & madera & $3.550 \pm 55$ & $1.600 \pm 55$ & $3.937-3.688$ & $1.987-1.738$ & $1.862-1.886\left({ }^{*}\right)$ \\
\hline Pic dels Corbs (V) & $?$ & cereal & $3.531 \pm 100$ & $1.581 \pm 100$ & $4.086-3.560$ & $2.136-1.610$ & $\left.1.873-1.880()^{*}\right)$ \\
\hline Cueva del Murciélago (C) & URG-342 & carbón & $3.520 \pm 90$ & $1.570 \pm 90$ & $3.994-3.565$ & $2.044-1.615$ & $1.829-1.855(n)$ \\
\hline Orpesa la Vella $(\mathrm{C})$ & $1-15844$ & carbón & $3.510 \pm 100$ & $1.560 \pm 100$ & $3.994-3.549$ & $2.044-1.599$ & 1.821 \\
\hline Orpesa la Vella (C) & $\mathrm{l}-15902$ & carbón & $3.510 \pm 100$ & $1.560 \pm 100$ & $3,994-3.549$ & $2.044-1.599$ & 1.821 \\
\hline Cati Foradà (A) & BIRM-199 & cereal & $3.502 \pm 150$ & $1.552 \pm 150$ & $4.152-3.392$ & $2.202-1.442$ & $1.822-1.845(*)$ \\
\hline Orpesa la Vella $(\mathrm{C})$ & $1-15860$ & carbón & $3.500 \pm 100$ & $1.550 \pm 100$ & $3.989-3.544$ & $2.039-1.594$ & 1.816 \\
\hline Lloma Redona (A) & ET1042? & carbón & $3.500 \pm 60$ & $1.550 \pm 60$ & $3.918-3.626$ & $1.968-1.676$ & 1.822 \\
\hline Orpesa la Vella $(\mathrm{C})$ & 1.15845 & carbón & $3.470 \pm 100$ & $1.520 \pm 100$ & $3.936-3.472$ & $1.986-1.552$ & 1.769 \\
\hline Orpesa la Vella (C) & $1-9869$ & carbón & $3.450 \pm 95$ & $1.500 \pm 95$ & $3.926-3.468$ & $1.976-1.518$ & $1.747-1.780(*)$ \\
\hline Orpesa la Vella (C) & $\mid-130+3$ & carbon & $3.450 \pm 90$ & $1.500 \pm 90$ & $3.911-3.472$ & $1.961-1522$ & 1.741 \\
\hline Orpesa la Vella $(\mathrm{C})$ & I-15881 & carbón & $3.420 \pm 100$ & $1.470 \pm 100$ & $3.914-3.452$ & $1.964-1.502$ & 1.733 \\
\hline Mas d'Abad (C) & $1-8936$ & carbón & $3.410 \pm 90$ & $1.460 \pm 90$ & $3.882-3.459$ & $1.932-1.509$ & 1.720 \\
\hline Cabezo Redondo (A) & GR-5109 & madera & $3.320 \pm 55$ & $1.370 \pm 55$ & $3.649-3.445$ & 1.699-1.495 & $1.597-1.587\left\langle^{\star}\right\rangle$ \\
\hline Can Ballester (C) & $1-10463$ & carbón & $3.310 \pm 95$ & $1.370 \pm 95$ & $3.731-3.346$ & $1.781-1.396$ & 1.588 \\
\hline El Torrelló $(C)$ & $1-7250$ & carbón & $3.300 \pm 90$ & $1.350 \pm 90$ & 3.723-3.345 & $1.773-1.395$ & $1.584-\left({ }^{\star *}\right)$ \\
\hline El Torrelio $(\mathrm{C})$ & $1-6937$ & carbón & $3.265 \pm 90$ & $1.315 \pm 90$ & $3.695-3.326$ & $1.745-1.376$ & $1.560-1.556(*)$ \\
\hline Orpesa la Vella (C) & CSIC-345 & carbón & $3.210 \pm 70$ & $1.260 \pm 70$ & $3.587-3.262$ & $1.637-1.312$ & $1.474-1.260\left(^{*}\right)$ \\
\hline Peña Negra $(\mathrm{A})$ & GAK9773 & hueso & $3.200 \pm 120$ & $250 \pm 120$ & $3.691-3.106$ & $1.741-1.156$ & $1.448-(*)$ \\
\hline Orpesa la Vella (C) & $1-15882$ & carbón & $3.170 \pm 100$ & $1.220 \pm 100$ & $3.625-3.144$ & $1.675 \cdot 1.194$ & 1.434 \\
\hline Cueva del Murciélago (C) & UGR-342 & carbón & $3.030 \pm 110$ & $1.080 \pm 110$ & $3.461-2.935$ & $1.511-985$ & $1.248-1.265\left(^{*}\right)$ \\
\hline Mas d'Abad (C) & $1-8935$ & carbón & $2.960 \pm 85$ & $1.010 \pm 85$ & $3.280-2.924$ & $1.330-974$ & 1.152 \\
\hline Abric de Les Cinc (C) & I-10466 & carbón & $2.920 \pm 90$ & $970 \pm 90$ & $3.274-2.842$ & $1.324-898$ & 1.324-1.144(*) \\
\hline Peña Negra $(A)$ & GAK9774 & carbón & $2.810 \pm 140$ & $860 \pm 90$ & $3.350-2.711$ & $1.400-761$ & $1.080-(* *)$ \\
\hline Torrelló del Boverot (C) & I-16723 & carbón & $2.720 \pm 90$ & $770 \pm 90$ & $3.075-2.710$ & $1.125-760$ & 943 \\
\hline Peña Negra $(A)$ & CSIC- 360 & carbón & $2.690 \pm 50$ & $740 \pm 50$ & $2.872-2.743$ & $922-793$ & $857-856\left(^{*}\right)$ \\
\hline Peña Negra $(\mathrm{A})$ & CSIC-484 & carbón & $2.670 \pm 50$ & $720 \pm 50$ & $2.863-2.732$ & $913-782$ & $847-827\left(^{*}\right)$ \\
\hline Peña Negra $(\mathrm{A})$ & CSIC- 410 & carbón & $2.580 \pm 50$ & $630 \pm 50$ & $2.776-2.478$ & $826-528$ & $\left.677-792()^{*}\right)$ \\
\hline
\end{tabular}

Figura 1. Relación de yacimientos de la Edad del Bronce en el Pais Valenciano con dataciones absolutas. 

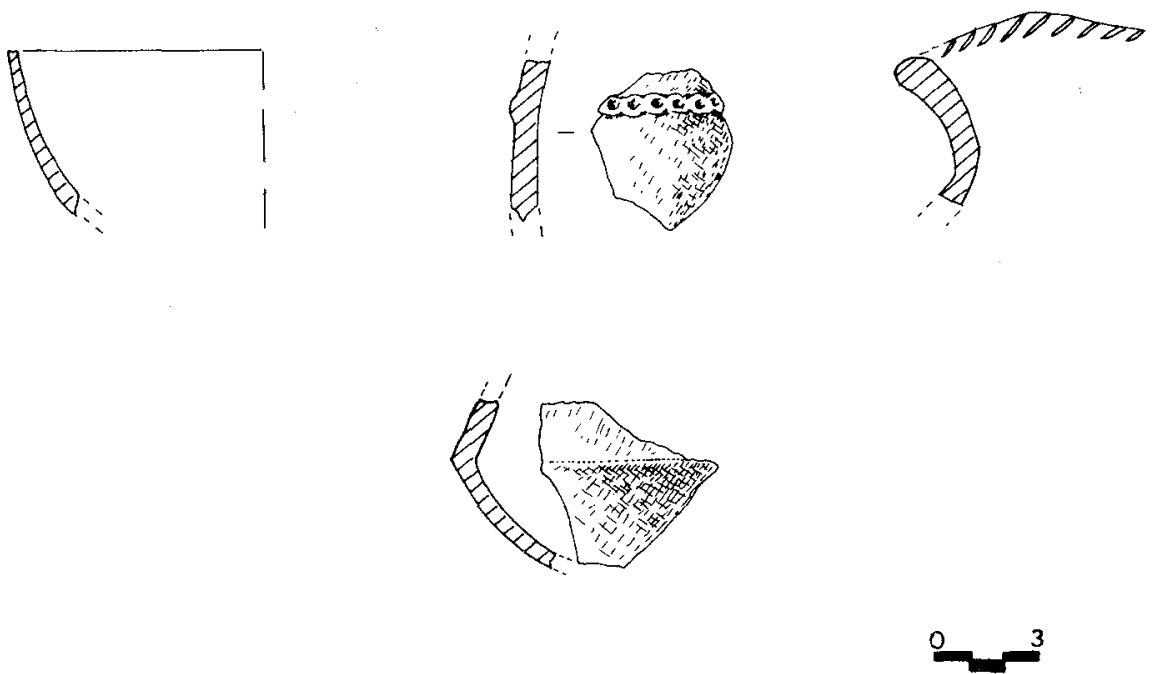

Figura 2. Cerámicas de los Corte 4 del Forat de Cantallops. Según C. Olaria y F. Gusi).

Se considera (Gusi Jener, 1984: 156) que este yacimiento del Forat de Cantallops es, con la Cova Puntassa de Corachar, representativo de la facies de raiz cazadora-pastoril del Maestrazgo, caracterizada por "cerámicas decoradas con gruesos cordones aplicados a las paredes de las vasijas, y también con incisiones angulares tipo chevrons, puntas de flecha en sílex o hueso, romboidales y de pedúnculo y aletas" (Gusi Jener, 1984: 156).

Estas cerámicas decoradas con gruesos cordones también se registran en otras cuevas con dataciones absolutas. Del Nivel superficial// del Covacho de Can Ballester se dispone de una datación del 1.588 cal ANE $\mathrm{m}$ cuyo "contexto arqueológico corresponde a materiales cerámicos del Bronce Medio/Final» (Olaria, 1977: 279), algunas de cuyas formas recuerdan a otras de Mas d'Abad (figuras 3 y 4), de la que se conocen dos dataciones, una del Nivel II -1.720 cal ANE $m-$ y la otra del Nivel I -1.152 cal ANE m- (Gusi, 1975; Olaria, 1977), este último asociado a enterramientos humanos con un mínimo de 13 individuos (Viñas, Campillo y Miquel, 1976). Otras dos dataciones proceden de la Cueva del Murciélago (Palomar, 1986 y 1990/91), una de ellas - 1.829 cal ANE m- corresponde al Nivel $V$, en el que no se localizaron materiales arqueológicos (Palomar, 1986: 439-441), mientras la otra -1.248 cal ANE m-procede de la capa inferior del Nivel IV con materiales del Bronce Final, entre los que se encuentran cerámicas de base plana, y fragmentos decorados con 

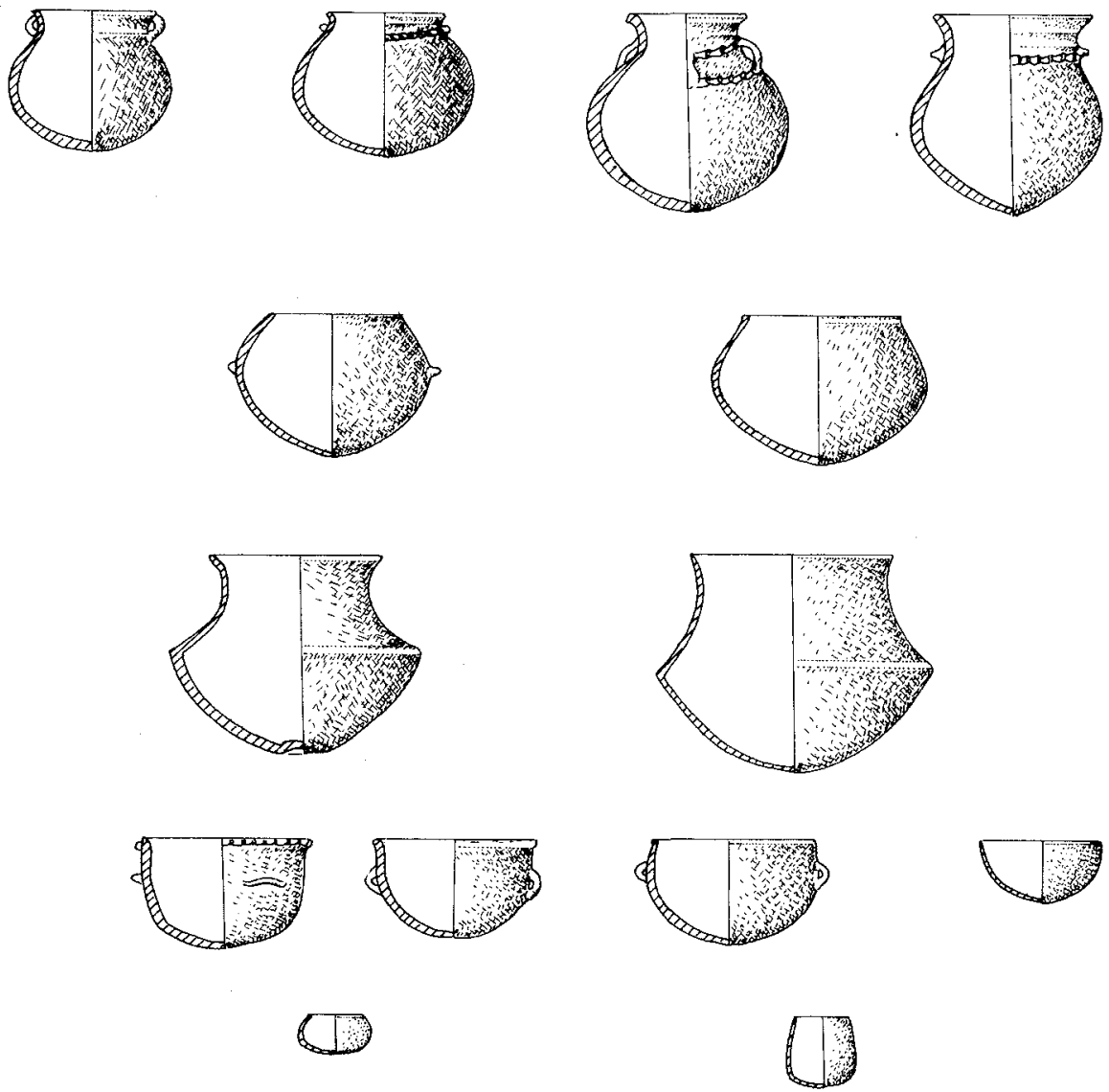

Figura 3. Mas d'Abad. Tipos cerámicos del Nivel I/Superficial (a distinta escala). Según F. Gusi y C. Olaria.

cordones y, excepcionalmente - sólo un fragmento por cada tipo-, con excisiones, incisiones y puntillado. Un tercer análisis de este mismo yacimiento fecha -330 DNE- el Nivel III donde se mezclaban materiales a mano y a torno. Por último, del Abric de Les Cinc se dispone de una datación del $1.324 \mathrm{cal}$ ANE m para el Nivel IV A en el que se recogieron 682 fragmentos cerámicos (figura 5 ) "de buena calidad con tratamientos de engobe y bruñido especialmente realizados en las vasijas carenadas" (Junyent et alii, 1982/83: 97).

Para los niveles preibéricos del Torrelló de Onda se cuenta con dos dataciones absolutas. La más antigua -1.584 cal ANE m-, que corresponde a una muestra del nivel III de la Trinchera Sur "compuesto por un nivel 

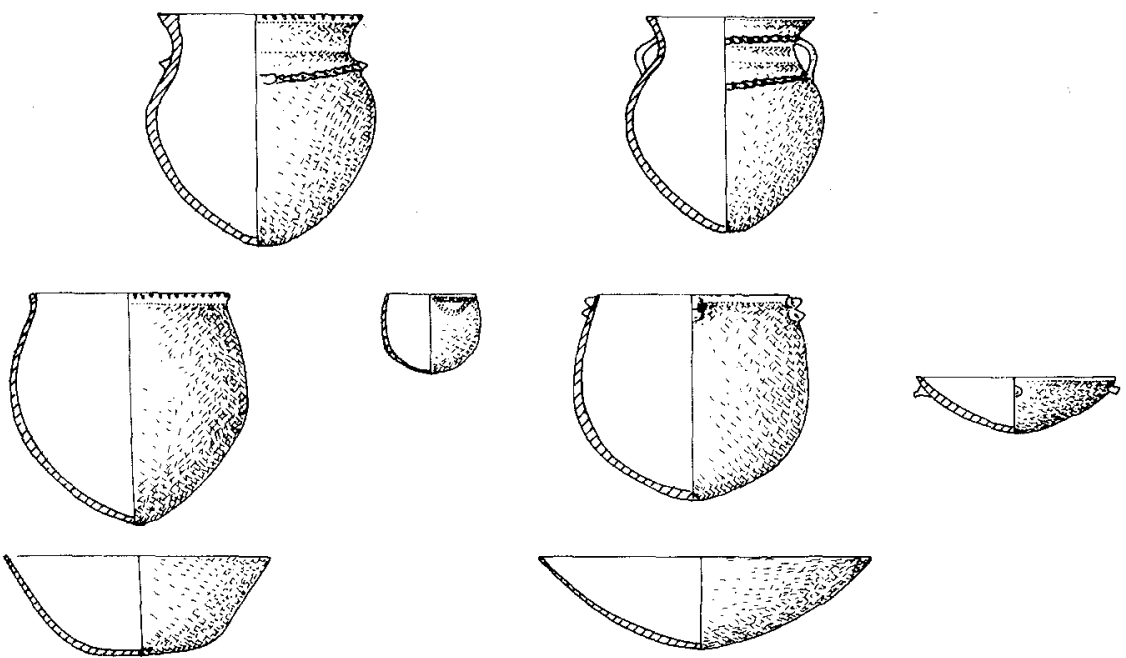

Figura 4. Mas d'Abad. Tipos cerámicos del Nivel II (a distinta escala). Según F. Gusi y C. Olaria.

carbonoso de aspecto ceniciento" (Gusi Jener, 1974: 41), ha sido rechazada "por desviación tipo muy elevada» (Castro Martínez, Lull y Micó: 1996). Sin embargo, los dos únicos fragmentos cerámicos publicados de este nivel, pertenecientes al cuerpo de dos vasijas carenadas (figura 6: 14 y 15), son similares a otras cerámicas de los niveles II y III A del Cuadro Q3 , datado el 1560 cal ANE m, procendente de una bolsada de carbón en la zona de contacto entre ambos niveles, aunque los perfiles carenados son más abundantes en el primero.

El Torrelló del Boverot es un yacimiento en altura con una larga ocupación y materiales que abarcan desde el Epipaleolítico hasta momentos avanzados del siglo XII DNE. Sobre una ocupación del Bronce Medio, sólo atestiguada por materiales cerámicos procedentes de actuaciones clandestinas (Clausell Cantavella, 1997), se indica otra del Bronce Final, a la que se asocia la datación absoluta -943 cal. ANE m-, con la que se relacionan "construcciones de piedra de mediano tamaño trabadas con barro, conformando un recinto o habitación de planta oval, que se asienta directamente sobre la roca» (Clausell Cantavella, 1997: 27), confirmando de este modo que la ocupación anterior no se extiende por todo el yacimiento, en el caso de que los materiales del Bronce Medio publicados pertenecieran al yacimiento. De este nivel, o niveles, del Bronce Final sólo se ha señalado la presencia de cerámicas con decoración acanalada, cordones e incisiones que se relacionan con los 

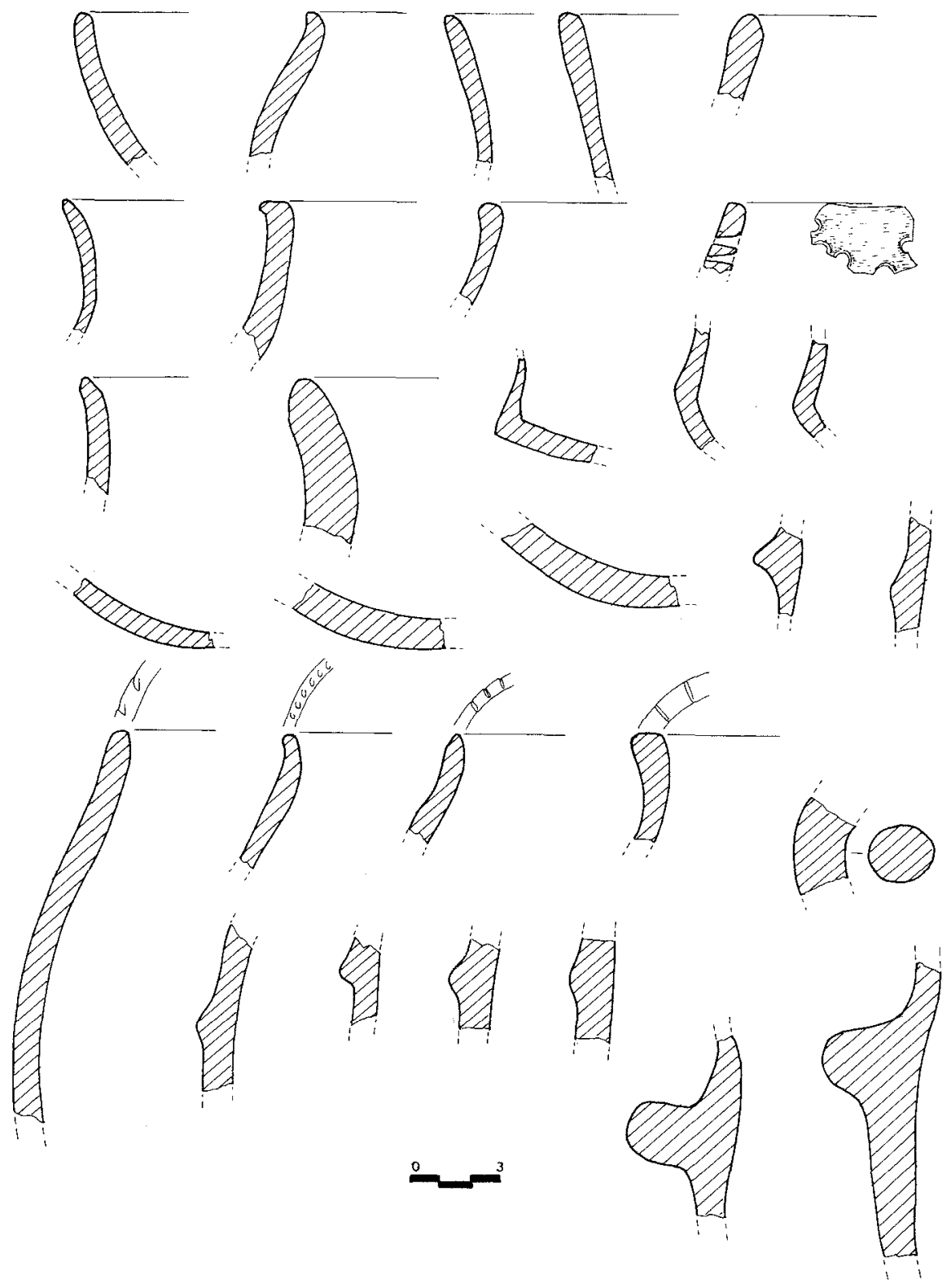

Figura 5. Abric de Les Cinc. Nivel IVa. Según Junyent et alii. 

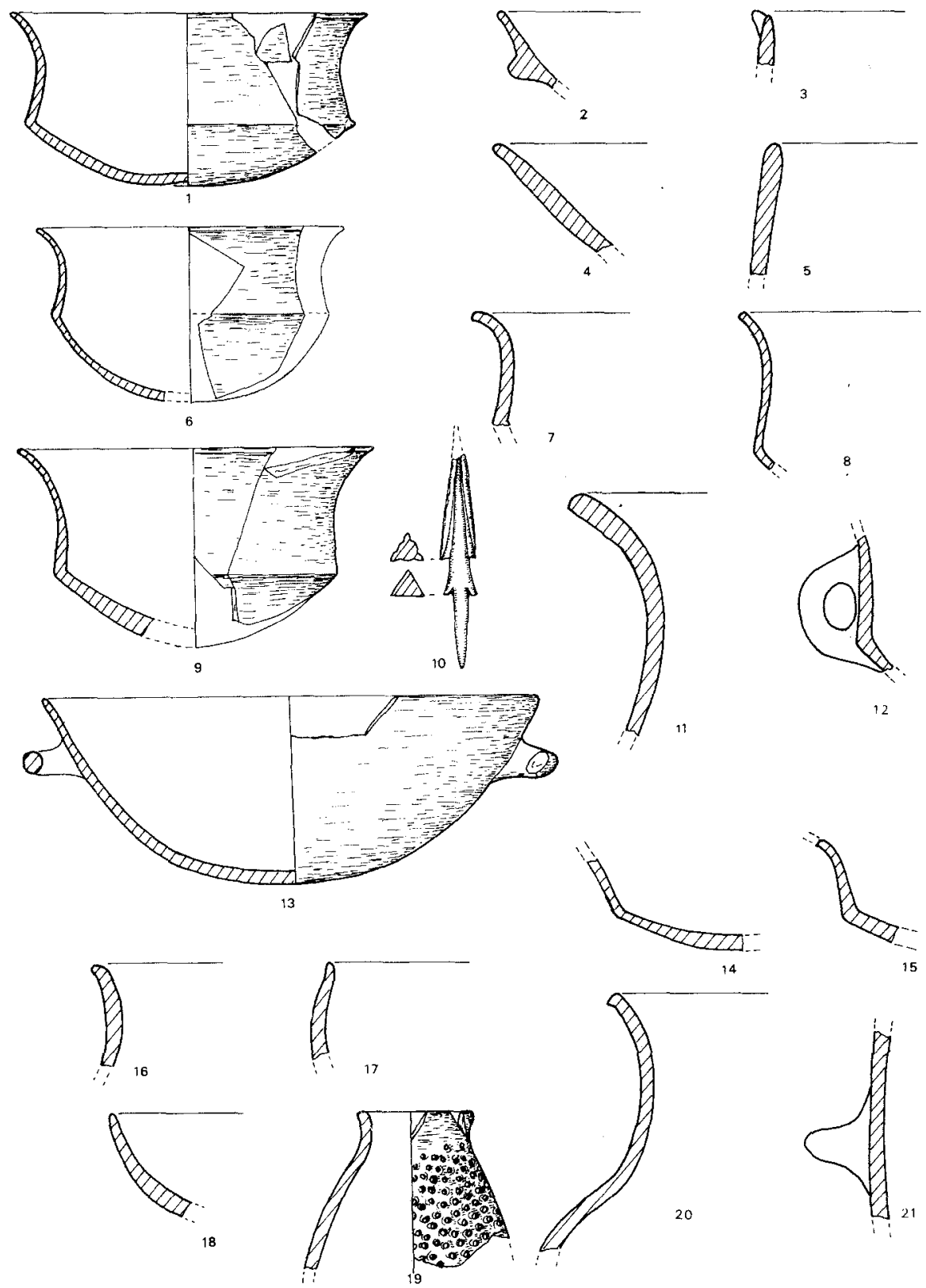

Figura 6. Torelló de Onda. 1-9, 11-13: Cuadro 3, nivel Il; 16-21: Cuadro 3, nivel III; h/ 14 y 15: Nivel III de la Trinchera Sur. Según F. Gusi. 
Campos de Urnas del Bajo Aragón y «de al menos dos hornos de reducidas dimensiones, ..., conformados por arcilla amasada, los cuales se debieron inutilizar en un momento avanzado del bronce final, no estando en relación con los materiales fenicio-occidentales» (Clausell Cantavella, 1995: 100).

La serie de dataciones más completa procede del yacimiento castellonense de Orpesa la Vella (Gusi y Olaria, 1995: 147-148). De éstas una permite datar la fortificación musulmana superpuesta al poblado de la Edad del Bronce -1.020 DNE-, cuatro se consideran altas y que no corresponden al contexto arqueológico -3.452 cal ANE $m-$ (nivel 5, QVIA), 3.253 cal ANE $m$ (nivel 5, Q-V), 2.083 cal ANE m (nivel 1, Q-VIA) y 1.741 cal ANE m (nivel 8, Q-VIA) y una baja según el contexto arqueológico que, sin embargo, se incluye en el Bronce Medio - 1.8121 cal ANE $\mathrm{m}$ - (nivel Q-XVIII), datación que se repite, considerándola ahora correcta, en otro análisis de nivel 2,Q-VIII. De las restantes, dos han sido publicadas y asociadas a materiales arqueológicos. Corresponden al 1.747 cal ANE $m$ (nivel 4, Q-2) y 1.474 cal ANE m (nivel 4, Q-4). Ambas se consideran del Bronce Medio (Gusi y Olaria, 1995: 148), de la Fase B del yacimiento caracterizada (figura 7) por «abundante cerámica carenada. Alto porcentaje de bruñido de excelente calidad, a la vez que se aprecia también un fuerte porcentaje de piezas de calidad basta y sin ningún tipo de engobe. Menor proporción de cerámica decorada con cordones. La decoración de incisiones en el labio es bastante frecuente,... son frecuentes las bases cóncavas, junto a las planas» (Gusi y Olaria, 1977: 97). El yacimiento en opinión de uno de sus excavadores «se aparta considerablemente del aspecto que ofrecen los pequeños y pobres poblados del interior. La excepcional arquitectura de sus viviendas, las complejas estructuras de tipo probablemente ritual y las importantes defensas de fortificación, parece que indican la existencia de una tradición cultural distinta a la que hasta ahora nos presentaban los asentamientos del llamado Bronce valenciano" (Olaria, 1987: 18). De interés puede considerarse los resultados metalográficos publicados (Rovira, Montero y Consuegra, 1997: 146-147), entre los que destacan dos puntas de flecha de aletas del Bronce Medio, con un porcentaje de estaño del 2.803 y $4.410 \%$, mientras para los restantes objetos se añade el signo de interrogación tras las siglas del Bronce Medio con un porcentaje de estaño que oscila entre el $2.311 \%$-fragmento lámina-y el $19.67 \%$ - fragmento de anillo-, mientras uno de ellos - fragmento de punta de flecha- posee un porcentaje de estaño del $11.26 \%$ y de $1.505 \%$ de plomo.

Sólo disponemos de cinco dataciones para yacimientos de la actual provincia de Valencia. Cuatro pertenecen a la Lloma de Betxí —del 2.126 

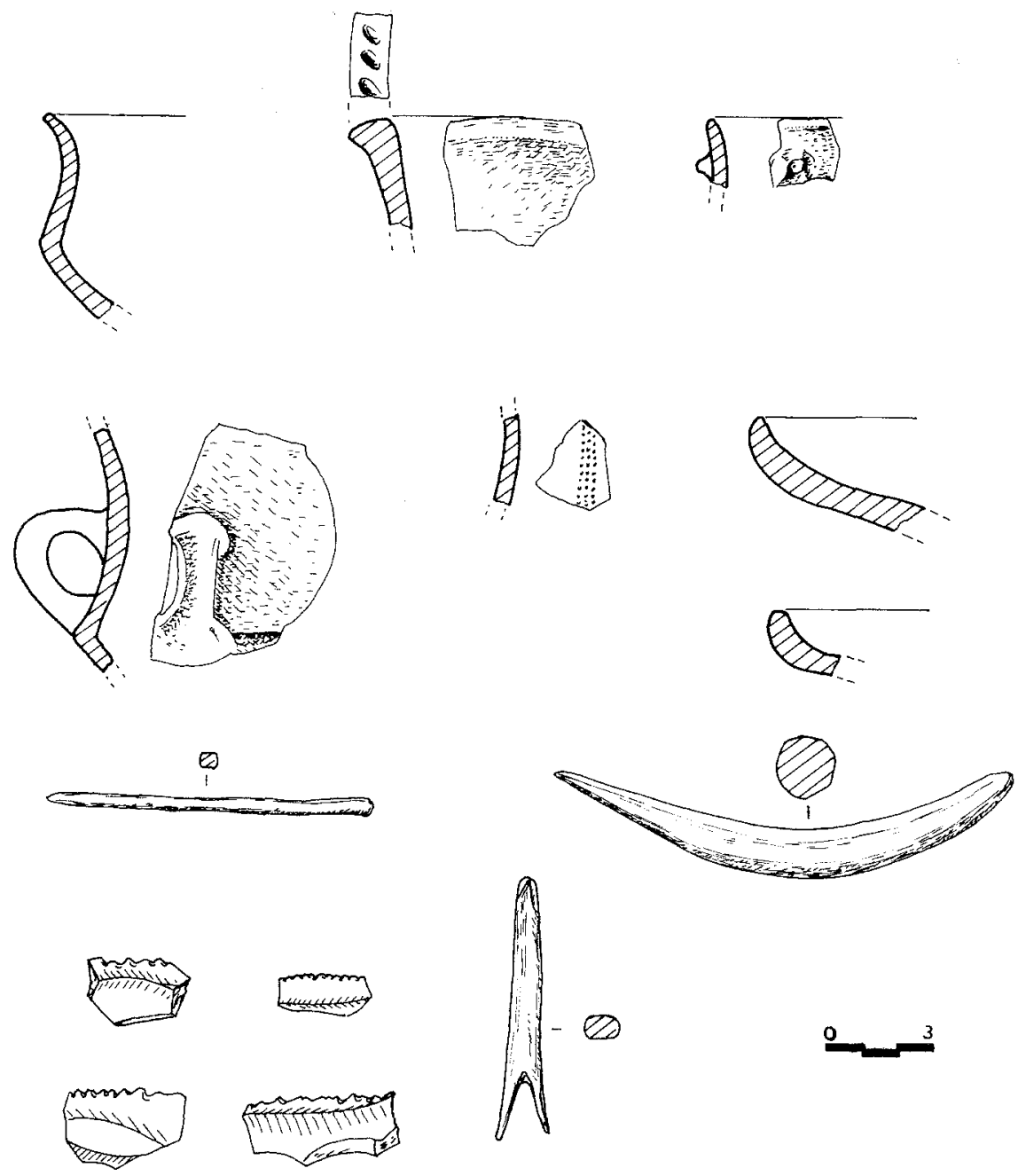

Figura 7. Orpesa la Vella. Nivel 4 de los Cortes 2 y 4 . Según F. Gusi y C. Olaria.

cal ANE $m$ al 1.814 cal ANE m- y se han obtenido del análisis de maderas localizadas en el interior de la gran edificación de la parte superior del cerro (De Pedro Michó, 1990), que en la actualidad se asocian, según comunicación personal de su excavadora, al derrumbe del primer momento de ocupación del yacimiento cuyos materiales, todavía inéditos, "constituyen un conjunto singular formado por más de 130 vasos cerámicos en el caso de la Habitación I entre los que no ha aparecido nada decorado a ex- 
cepción de las series de mamelones o pequeñas digitaciones en el labio. Las formas cerámicas son asímismo las habituales en los poblados de la Edad del Bronce, por lo que apenas se pueden hacer precisiones sobre la evolución de la cultura material a lo largo de su ocupación durante el Bronce Pleno" (Martí Oliver y De Pedro Michó, 1997: 72).

La datación del Pic de les Corbs - 1.873 cal ANE m-corresponde al trigo carbonizado hallado en el interior de una vasija en 1955 (Tarradell, 1965). Esta fecha es considerada válida para un poblado que perdura hasta los siglos VIII-VII a.C. (Barrachina, 1989: 40).

Para el territorio alicantino no disponemos de dataciones absolutas de los yacimientos identificados como argáricos. En cambio, las dos fechas más elevadas corresponden a yacimientos ubicados a no excesiva distancia de aquellos y para los que en ocasiones y sin argumentos sólidos se ha propuesto una relación con el Bronce Argárico, el Valenciano - a una de las facies de esa indefinida Edad del Bronce del País Valenciano. Sobre una de estas dataciones hemos manifestado algunas reservas, mientras para la otra la información disponible sobre la muestra es algo más precisa. En efecto, la datación de Serra Grossa -2.224 cal ANE m- se obtiene de cereales recogidos en 1932 por el Padre Belda, sin que exista información sobre su situación estratigráfica y, por tanto, de los materiales arqueológicos asociables. La muestra formaba parte de los tres kilogramos de cereal carbonizado depositados (Llobregat, 1969: 54) en una vitrina del Museo Arqueológico Provincial de Alicante en el interior de un bote de cristal abierto durante mucho tiempo - no sabemos si la vitrina era una de las que también durante mucho tiempo permanecieron abiertas o sin cristal-. Se ha sugerido una contaminación de la muestra (Llobregat, 1971: 96) y, lo que me parece más probable (Hernández Pérez, 1997: 97), teniendo en cuenta la personalidad del P. Belda y los avatares por los que pasó el Museo en los años de su dirección, la posible mezcla de cereales de otros yacimientos. Sobre el contexto arqueológico de la muestra no disponemos de información, salvo la general del yacimiento (figura 8), en el que ya el propio E. Llobregat señaló la calidad de las pastas cerámicas, en su opinión diferentes a las del Bronce Valenciano, y la abundancia de fondos planos - casi un $20 \%$ del registro-, por lo que antes de conocer la datación absoluta se consideró que «habría de encajarse en los siglos anteriores a la eclosión de la cultura ibérica, entre el VIII y $\mathrm{V}$ antes de nuestra Era (Llobregat, 1969: 67).

La datación de Terlinques -2.202 cal ANE $m$ - se obtuvo de una madera recogida en excavaciones (Soler García y Fernández Moscoso, 

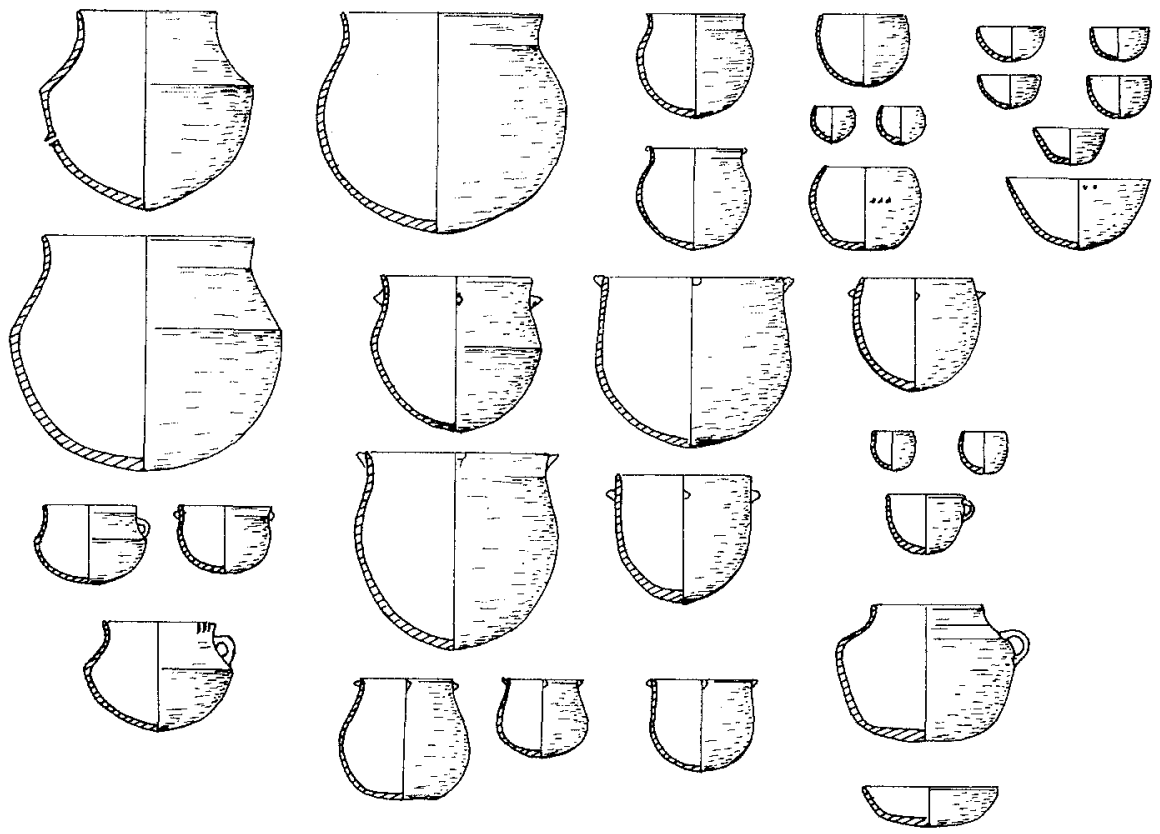

Figura 8. Serra Grossa. Según E. Llobregat.

1970, 32), sobre la que existe alguna confusión. En efecto, se citan «muestras de carbones» - sin precisar si lo analizado es de un mismo trozo o de varios-, recogidas en «un estrato de tierras negras, con cenizas y carbones", a una profundidad de $40-50 \mathrm{~cm}$, no continuándose la excavación en este punto, aunque la roca virgen podría situarse a una profundidad de $50-60 \mathrm{~cm}$. Según M. Tarradell la excavación se realizó en una zona que "constituye la última fase de vida del poblado» y los carbones "a un nivel del suelo de la vivienda" y "a su nivel de destrucción». No existe duda alguna sobre los materiales arqueológicos asociados a esta datación (figura 9), aunque no pueda establecerse idéntica relación con los hallados en superficie, entre ellos un colgante o anillo de oro y una espiral de plata, que podrían pertenecer a una ocupación posterior, si bien curiosamente M. Tarradell señalara que «los elementos dispersos podrían pertenecer a un hipotético nivel anterior» (Tarradell, 1970: 23).

Las dos dataciones del Mas del Corral -2.175 cal ANE m y 2.097 cal ANE $\mathrm{m}$ - proceden de "carbones del momento que se puede asignar en principio al Bronce Pleno" (Trelis Martí, 1992: 87), del que a 

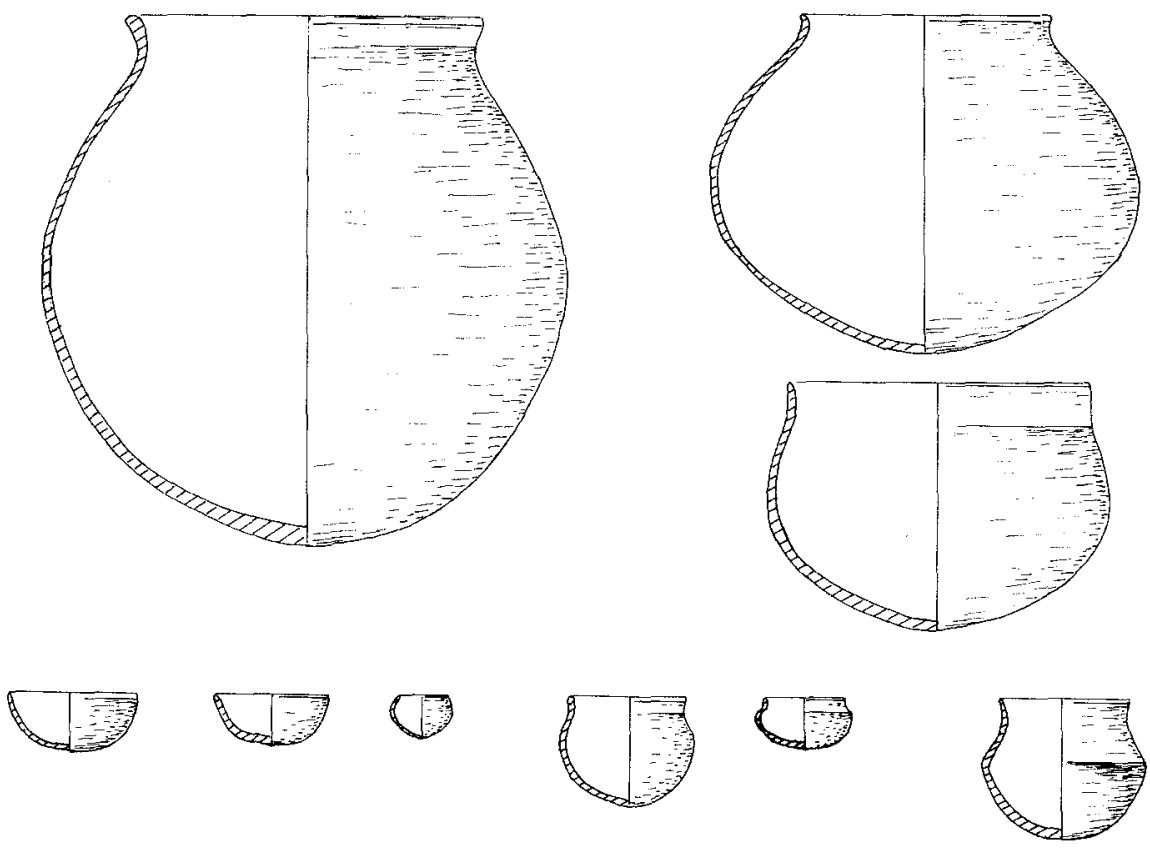

Figura 9. Terlinques, Departamento I. Según J.M $M^{a}$ Soler.

nivel de materiales arqueológicos se señala, sin la correspondiente información gráfica, la presencia de "grandes vasijas para almacenamiento, cuencos, una vasija con carena a media altura y un asa de cinta...-, al igual que la industria ósea - punzones biselados y un mango para punzón metálico-y los restos de fauna" (Trelis Martí, 1992: 87).

La datación de Catí Foradà -1.822 cal ANE m- se obtuvo de cebada carbonizada recogida en una cata de $2 \times 1 \mathrm{~m}$ (Walker, 1981). De este yacimiento se han descrito 56 fragmentos, todos de bordes, dos carenas sin bordes y varias paredes con mamelón (Jover Maestre y Segura Herrero, 1995: 133-134).

Para las excavaciones de las últimas décadas sólo disponemos de la datación en la Lloma Redona -1.822 cal ANE m-. Se trata de un poblado en altura en el centro del corredor que une el Vinalopó con el Camp d'Alacant - donde se ubica la llleta dels Banyets y Serra Grossa- con un único nivel de ocupación (Navarro Mederos, 1986 y 1987), extraordinariamente afectado por actuaciones clandestinas de las que conocemos sus materiales arqueológicos (figura 10). 

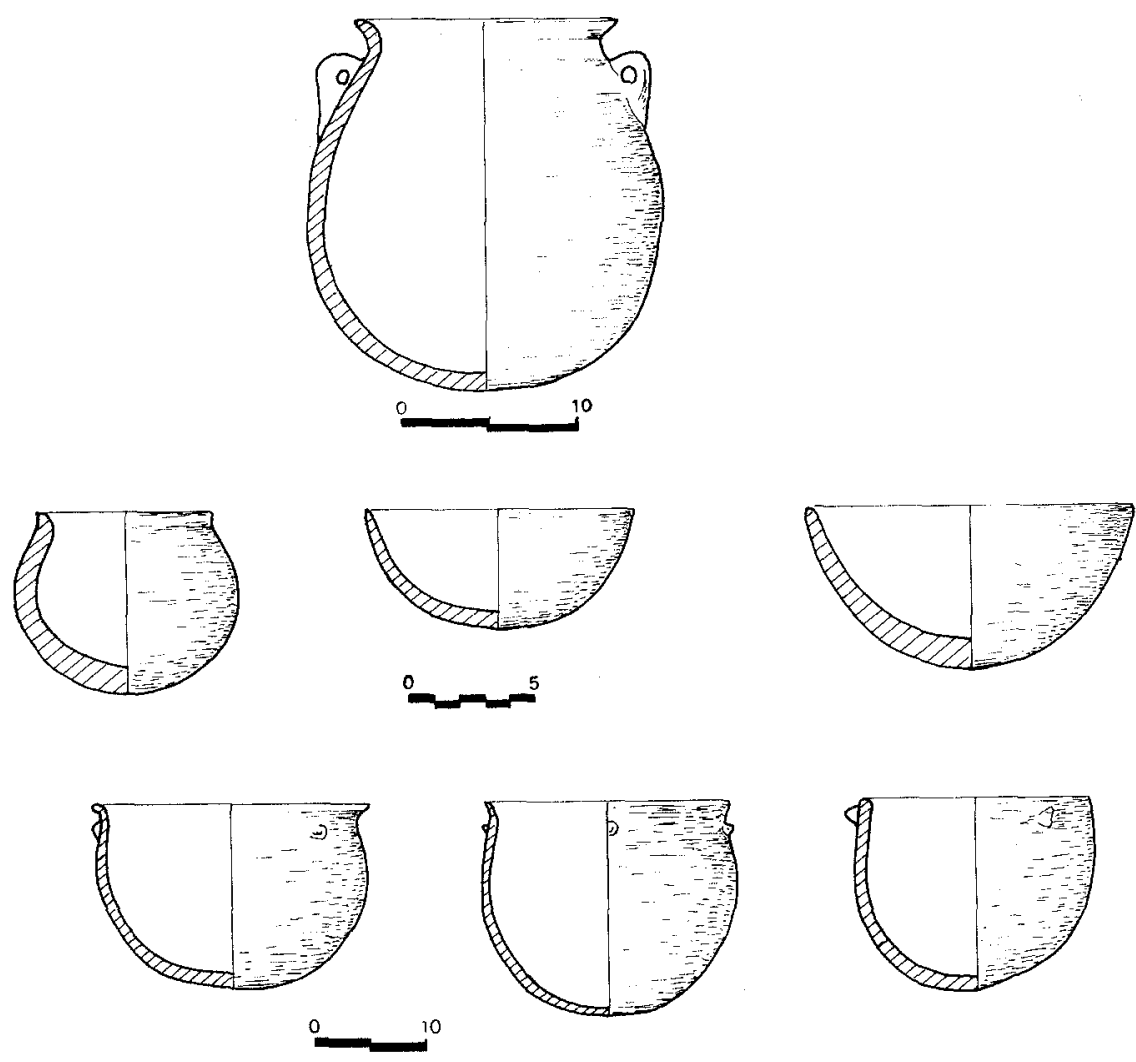

Figura 10. Lloma Redona. Según J.F. Navarro.

De las dos dataciones del Cabezo Redondo la información arqueológica es bastante precisa. Una de ellas $-1.862 \mathrm{cal}$ ANE $\mathrm{m}$ - procede de un tronco de madera bajo la hilada inferior del muro oriental del Departamento VII, por lo que se ha sugerido su relación con la ocupación inicial del yacimiento 0 , al menos, de este Departamento. Sin embargo, entre los materiales recuperados en el nivel más profundo de este sector del Departamento (figura 11), con el que debería asociarse la construcción de sus paredes, se encuentra una vasija con ónfalo y decoración excisa, además de otras con la línea de carena en el tercio superior, y una punta de flecha con pedúnculo y aletas de sílex. La valoración tradicional de la segunda datación -1.597 cal ANE m- resulta aún más sorprendente. Se obtuvo de la madera de un poste de sustentación de la techumbre que se coloca en el momento inicial de ocupación de la vivienda o, al menos, al 

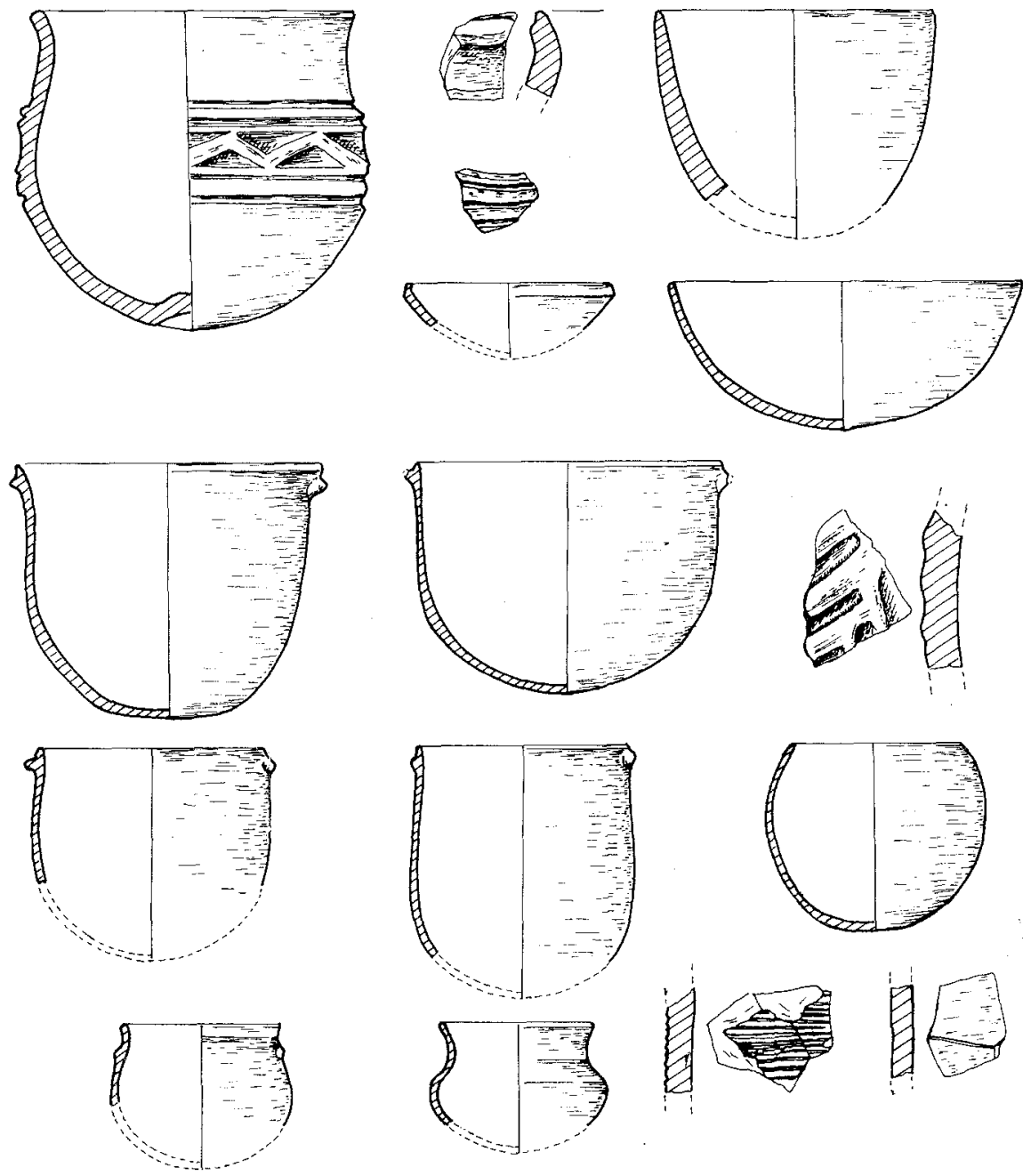

Figura 11. Cabezo Redondo. Departamento VII, nivel IV. Según J.Má Soler.

de una reforma, de la que por otro lado nada se indica por lo que suponemos que debió permaner en pie durante toda la ocupación del Departamento y, por tanto, todo su relleno arqueológico podría relacionarse con dicho tronco, aunque en principio fuera el nivel más profundo el que más próximo estuviera a la datación de la madera. J. M ${ }^{a}$ Soler identificó en el potente relleno de este Departamento hasta 5 niveles. En el superficial encontró un fragmento de cerámica a torno que asocia a las gen- 
tes de la necrópolis protohistórica del Peñón del Rey, que fecha en el siglo $\checkmark$ a.C. (Soler García, 1987: 77), mientras en el más profundo, con el que relaciona el poste analizado, registra la presencia de objetos de cerámica, piedra, sílex, barro, hueso, asta, concha y metal (figura 12), destacando entre estos últimos punta de flecha ojival con aletas y pedúnculo, similar a otras encontradas en el nivel II de este mismo Departamento.

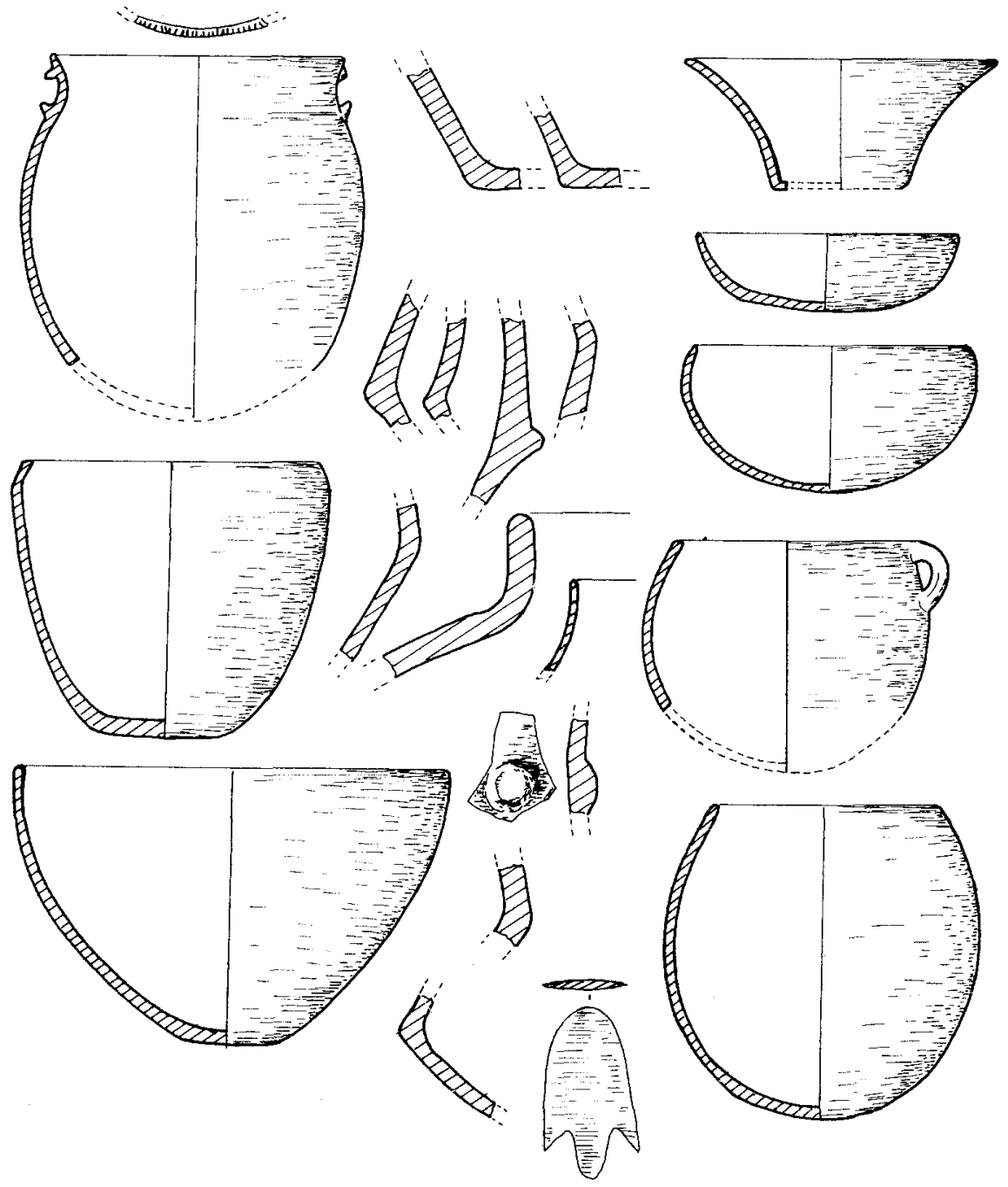

Figura 12. Cabezo Redondo. Departamento XV, nivel V. Según J.M $M^{a}$ Soler. 
Las dataciones absolutas de Alicante se completa con la serie de Peña Negra. Se trata de diez dataciones, de las que dos fueron obtenidas en el Laboratorio japonés de Gakushuin y las restantes del Instituto Rocasolano del C.S.I.C. De ellas nos interesa destacar aquí las relacionadas por A. González Prats con el Bronce Final - Horizonte Peña Negra I- ya que las restantes pertenen al período Orientalizante -Peña Negra II-. Según su excavador «de las muestras procesadas para la datación de C14, sólo dos entran en el marco cronológico deducido del análisis arqueológico" (González Prats, 1983: 271). Corresponden al Estrato Ilc del Fondo de cabaña del Corte 4⿳亠丷厂 , Sector IA, de la campaña de 1977 - 857 cal ANE m.- y al estrato Ilc2 del Corte C, Sector II, de la campaña de 1980 - 847 cal ANE m-. La primera, que data el momento de asentamiento sobre la roca de este Horizonte, es considerada por su excavador (González Prats, 1983: 271) "excesivamente baja, con un siglo de diferencia con la edad estimada para la formación del estrato inferior del Corte C de 1979», señalando que lo mismo cabría decir de la otra datación. De este último se ha publicado (González Prats, 1985) sus materiales arqueológicos (figura 13), entre los que se encuentran un arete de bronce y cerámicas groseras y finas, además de un fragmento de cerámica excisa, dos acanalados y veintitres incisos. Asimismo se han publicado las cerámicas asociadas a la datación del fondo de cabaña, en la que destacan (figura 14) los fondos planos y los fragmentos con carenas altas, además de «abundantes huesos de ovicaprinos y otros sin identificar más grandes, tal vez de bóvido o caballo; conchas marinas, cantos rodados quemados, placas agrietadas de hogar y piezas perforadas de barro crudo (González Prats, 1979: 116).

Es incuestionable el interés de estas dataciones absolutas para cualquier propuesta de periodización de la Edad del Bronce en las tierras valencianas al norte del Vinalopó. No obstante, es conveniente no olvidar que, con la excepción de la obtenida en Catí Foradà, todas han sido obtenidas de carbones o maderas, por lo tanto muestras de vida larga, y que muchos de éstos pertenecían a postes de sustentación de techumbres en poblados en los que se constatan varios niveles de habitación. Razonablemente habría que relacionar la datación con el nivel más antiguo, salvo que se produjeran remodelaciones posteriores, que de confirmarse podrían explicar algunas de las contradicciones entre la datación y los materiales que pretendidamente fecha. En muchos casos, como evidentemente ocurre en el Cabezo Redondo, se reaprovechan maderas «muertas» desde hace varios siglos.

$\mathrm{Si}$ estas dudas nos plantean dataciones para las que disponemos de publicaciones, tanto de estructuras como de materiales, creemos conveniente mantener en reserva todas aquellas de las que carecemos de in- 

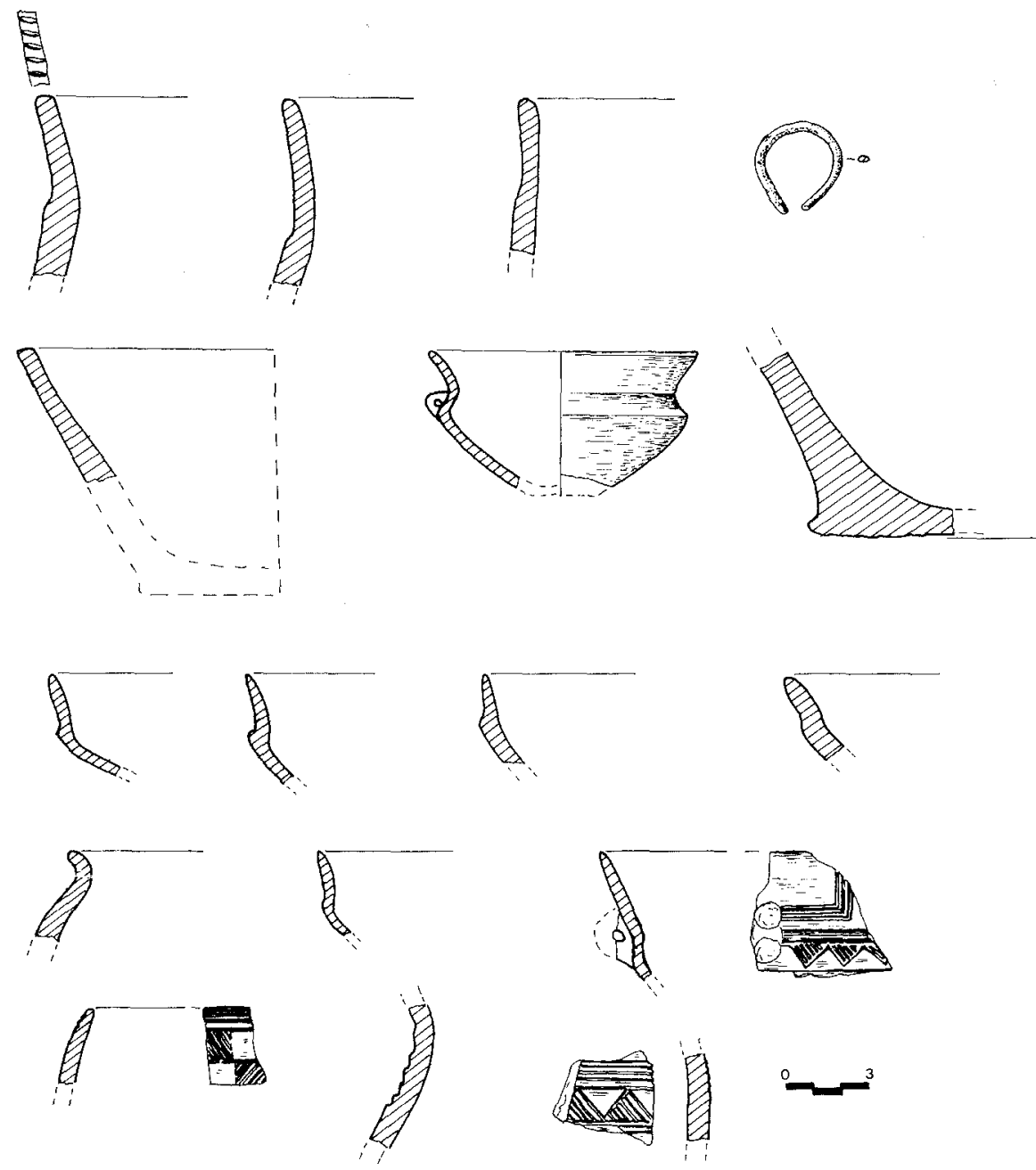

Figura 13. Peña Negra I. Corte C, estrato II c. Según A. González Prats.

formación sobre el origen de los carbones y el registro arqueológico. Es decir, prácticamente todas.

Sin embargo, no podemos prescindir radicalmente de todas estas dataciones, aún asumiendo el riesgo de una interpretación parcial, provisional e, incluso, errónea. Con los datos actualmente disponibles no es posible utilizar la periodización propuesta para el Bronce argárico (González, 1994: 23-24), aunque sea siempre un referente de extraordinario interés. 

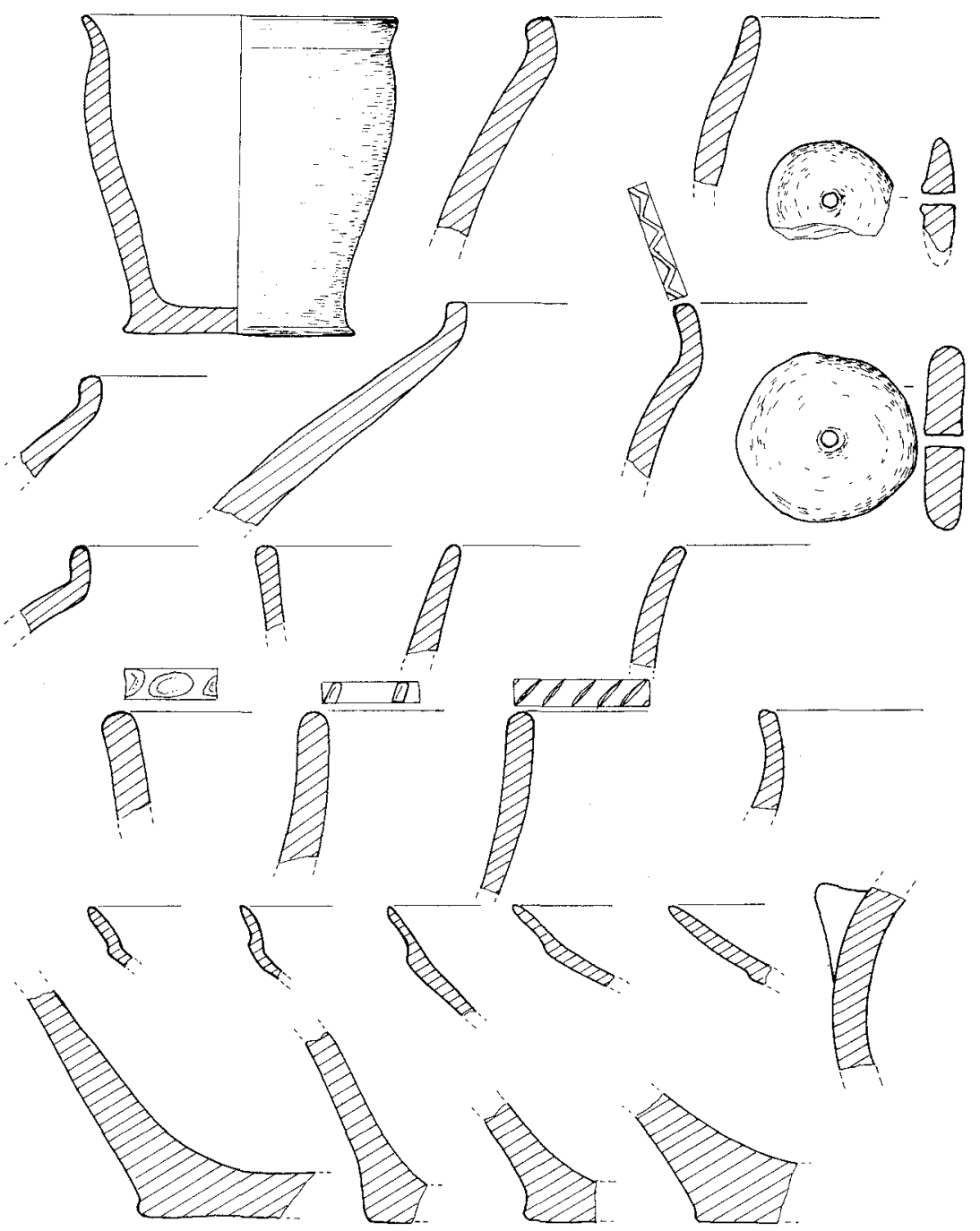

Figura 14. Peña Negra I. Corte 4 a, nivel ll c (fondo de cabaña). Según A. González Prats.

Por otro lado, consideramos que cualquier propuesta de periodización a partir de la simple agrupación de las fechas en tramos de siglos, independientemente del cómputo utilizado, es, en estos momentos y hasta que se publiquen los materiales asociados a ellas, un trabajo de escasa, por no 
decir nula, utilidad, aunque quizás si necesario como revulsivo que rompa el temor a toda propuesta.

Las fechas de Serra Grossa y Terlinques marcan el inicio de la Edad del Bronce en las tierras valencianas. Son coherentes con las dataciones para el Bronce Argárico y con las propuestas tradicionales sobre el origen de la Edad del Bronce en el País Valenciano, que lo hacen depender de aquel. Sobre esta cuestión no disponemos de nuevos argumentos a incorporar a los fijados en otras ocasiones (Hernández Pérez, 1986 y 1997).

La dos fechas del Mas del Corral, ligeramente más recientes, encajan, asimismo, con la tradicional visión de la influencia del sudeste en la formación de la Edad de Bronce en el interior montañoso de Alicante, aunque lamentablemente desconocemos los materiales y tipos de estructuras de esta ocupación inicial del yacimiento que permitiera compararlos con los Terlinques o Serra Grossa.

Podemos afirmar, por tanto, que en el tránsito entre el tercer y segundo milenios, en fechas calibradas, se ha producido en las tierras alicantinas la aparición del hábitat en altura. Éste es el elemento cultural que, en principio, mejor caracteriza a la Edad del Bronce, aunque en las tierras alicantinas del Vinalópo y Bajo Segura se asocie a momentos anteriores. En efecto, el hábitat en zonas bajas de valles y en las proximidades de las hipotéticas tierras de cultivo se considera, conjuntamente con el enterramiento múltiple en cueva natural, el elemento que caracteriza al Eneolítico, con la excepción, reiteramente repetida, de Les Moreres que por su situación en altura y sus fortificaciones naturales y artificiales se relacionaba con los poblados precampaniformes del Sudeste tipo Millares (González Prats, 1986). Las excavaciones posteriores permiten una diferente lectura al constatarse la presencia de cerámica campaniforme incisa «en toda la secuencia del poblado" (González Prats y Ruiz Segura, 1991/92: 19) y un abundante conjunto de objetos metálicos de idéntica filiación. En otros poblados en altura se ha localizado cerámica campaniforme siempre en un reducido número (Ruiz Segura, 1990; Soler Diaz, 1995), con la excepción del Promontori d'Aigua Dolça i Salada (Ramos Fernández, 1981 y 1986). De todos estos yacimientos interesa destacar por su proximidad a Terlinques los del Puntal de los Carniceros y Peñón de La Zorra, ambos en altura, "defendidos" por escarpes naturales y muros de piedra, y de pequeño tamaño - unos $100 \mathrm{~m}^{2}$ el Peñón de la Zorra y menos de $400 \mathrm{el}$ Puntal de los Carniceros (Soler García, 1981) - , en los que el registro de cerámica se reducía a unos veinte fragmentos incisos en el Puntal de los Carniceros (Soler García, 1981: 67) y a cinco, también incisos, en el 
Peñón de la Zorra (Soler García, 1981: 93). En el reducido registro de este último yacimiento -no debe olvidarse que Soler sólo hizo una cata de $2 \mathrm{~m}$ de lado-, se encuentra, además de varios dientes de hoz, un vaso carenado y un cuenco con asa de cinta vertical, dos formas cerámicas presentes en el registro de Terlinques y Serra Grossa, aunque en el primero no se conozcan asas de cinta.

Los enterramientos ubicados en las laderas de estos dos poblados de Villena aportan, asimismo, una información de extraordinario interés para el tema que nos ocupa. Del ajuar de la Cueva del Puntal de los Carniceros, en la que se inhumaron, al menos 5 cadáveres, destaca la presencia de una punta de flecha de sílex, una placa de sílex tabular y un arete de plata (Soler García, 1981: 83), del de la Cueva occidental del Peñón de la Zorra, de la que no se precisa el número de individuos, otra punta de flecha de sílex y otro arete de plata y, por último, del de la Cueva oriental del Peñón de la Zorra, con un sólo inhumando, un largo puñal de lengüeta, dos largas puntas de jabalina y, de nuevo, otro arete de plata (Soler García, 1981: 93-106). Por otro lado, en Terlinques se ha señalado la existencia de restos humanos en superficie, al pie de unos escarpes, y dos dientes infantiles en el Departamento II, al tiempo que no debemos olvidar la presencia en este yacimiento en altura de un arete de plata, puntas de flecha de sílex y de metal tipo Palmela y una placa de sílex tabular. No resulta aventurado señalar, a juzgar por sus registros arqueológicos, la contemporaneidad de todos estos yacimientos, en la línea que hemos propuesto en otras ocasiones al poner en relación el abandono de los poblados en llanura y, por tanto, su progresiva sustitución por el de altura con el "aumento demográfico del Eneolítico, que trae consigo la ocupación de nuevas tierras, la utilización de nuevos útiles adaptados a las nuevas necesidades y a la fragmentación de las estructuras sociales" (Hernández Pérez, 1986: 347), por que creemos que esta ubicación de los poblados en altura, que no olvidemos es el elemento que mejor caracteriza a la Edad del Bronce en las tierras valencianas, es un proceso independiente al campaniforme y a las influencias argáricas, aunque ambas hayan contribuido a acelerar un proceso de cambio social que se venía gestando y en el que los elementos campaniformes, siempre escasos en hábitats o en enterramientos, y la plata, de evidente origen argárico (Montero, Rovira y Gómez, 1995), eran objetos de prestigio para unas incipientes elites.

Retomado de nuevo la serie de dataciones absolutas destacan, asimismo, las dataciones de Lloma de Betxí, que demuestran que entre los siglos XXII y XIX a.C., en fechas calibradas, se podría situar la aparición de la Edad de Bronce en las comarcas centrales valencianas, mientras Orpesa la Vella permite idéntica consideración para Castellón. Esta tem- 
prana aparición de poblados en altura en estas zonas difícilmente puede ser explicada por influencia del Sudeste o del campaniforme. Por otro lado, al tratarse de poblados de compleja arquitectura, próximos a otros más pequeños, algunos de los cuales, con todas reservas propias del registro disponible, pueden ser comporáneos, podría revelar una incipiente jerarquización de éste y relacionarse a su vez con un proceso similar al de las tierras alicantinas.

Retomando la definición de B. Martí y J. Bernabeu para el Bronce Valenciano, recogida más arriba, estas dataciones absolutas en yacimientos de las tres provincias permiten remontar su aparición, al menos, a los inicios del II milenio cal. ANE como resultado de un lento proceso de cambio cultural que se ha ido generado lentamente en los siglos anteriores sin apenas presión externa, aunque no puedan descartarse influencias campaniformes y argárica, mucho más intensas en los yacimientos alicantinos del Vinalopó y del interior montañoso. La abundancia de elementos relacionados con las actividades agropecuarias, la organización del territorio y las propias características del hábitat revelan, como ya señalara en un extraordinario análisis M.Gil-Mascarell (1992), el papel de la agricultura y de la ganadería en la aparición y desarrollo de la Edad del Bronce en las tierras valencianas fuera de la órbita argárica. Se explica así la escasa incidencia de la metalurgia en este proceso y el tantas veces citado gradiente sur-norte en la distribución y variabilidad tipológica de los objetos metálicos. Por otro lado, la presencia de enterramientos en grietas o covachas próximas a los poblados podría responder a una fuerte tradición eneolítica en la que de lo múltiple se pasa lentamente a lo individual y al enterramiento en el interior o en las proximidades del poblado.

Es indudable que este proceso debe tener su reflejo en el registro arqueológico, tanto a nivel de ocupación del territorio como en los elementos culturales. No obstante, la información disponible no permite poder evaluar estos cambios y, por lo tanto, es imposible en estos momentos establecer fases dentro de esta Edad del Bronce, de ahí que en la bibliografía se emplee cada vez con mayor insistencia el término de Bronce Pleno para referirse a la Edad del Bronce con anterioridad al Bronce Tardío.

Para este Bronce Tardío se ha propone en el Sudeste una cronología entre el 1615 y 1375 cal ANE (Castro, Lull y Micó, 1996: 171) y en él se incluye el Cabezo Redondo como uno de los yacimientos que permite caracterizarlo. Para este tramo cronológico disponemos en el País Valenciano de 6 dataciones, ya que por las razones señaladas más arriba se debe rechazar la de Peña Negra del $1.448 \mathrm{cal}$ ANE m. Una de estas dataciones pertenece al Cabezo Redondo y las restantes a yacimientos de 
Castellón -2 de Orpesa la Vella, 2 al Torrelló de Onda y 1 a Can Ballester-. El Bronce Tardío fue identificado en su momento a partir de determinadas formas y decoraciones cerámicas, la generalización de la metalurgia de bronce y la aparición de algún otro elemento cultural, como ciertas formas de punzones de hueso, pesas de telar o de objetos de metal. A nivel del País Valenciano es la cerámica tipo Cogotas I y, en mucha menor medida, los cuencos y cazuelas carenados de borde vertical, los elementos que se han utilizado para incluir un determinado yacimiento en el Bronce Tardío. Sobre la primera se ha llamado la atención (Delibes de Castro y Abarquero Moras, 1997: 120) sobre su escasez, "tanto en lo que se refiere al número de yacimientos afectados como a la cantidad de vasos representativos». Los mismos autores realizan un exhaustivo análisis de toda la información disponible para plantearse «la posibilidad de que el Bronce Tardío no sea más que una construcción irreal que sólo afectaría a determinados enclaves, aquellos que presentan cerámicas de Cogotas I, mientras que, en el mismo momento, podrían funcionar otros poblados pertenecientes a los mismos grupos y sin grandes diferencias, en los que no se hubieran aportado las citadas especies procedentes del interior de la Península» (Delibes de Castro y Abarquero Moras, 1997: 126). En línea con las reflexiones de estos autores creemos que el Bronce Tardío es un período a redifinir en el País Valenciano y en el que se debe establecer una clara diferenciación territorial no sabemos si real o fruto de una desigual información.

Las recientes excavaciones confirman al Cabezo Redondo como el yacimiento que podría definir al Bronce Tardío de las comarcas meridionales valencianas. Estas excavaciones y el reestudio de las antiguas indican que las estructuras actualmente visibles corresponde claramente al Bronce Tardío y que de la ocupación anterior, de existir, no se han constatado restos arquitectónicos. Es cierto que en algunos puntos los muros se apoyan o cortan un nivel de tierras verdosas con escasos y poco significativos restos cerámicos y una mayor cantidad de fauna menos troceada que la de los niveles superiores, sin elementos que faciliten su cronología relativa y, al menos hasta este momento, sin carbones que permitan su datación absoluta. Esta misma tierra rellena los huecos de la roca en una evidente disposición antrópica - y trasladada de otro lugar- para obtener superficies horizontales sobre los que se construye el suelo con el que se puede relacionar la construcción de los muros visibles. Es indudable que estos restos proceden de una ocupación anterior de la que no podemos precisar su cronología ni su ubicación y de la que sólo podemos señalar que gana en potencia en las partes bajas del poblado, colocándose en paquetes de diverso grosor, en algunas ocasiones con un cierto intervalo 
de tiempo a juzgar por la delgada capa de sedimentos de aportación eólica, a veces mezclados con materia orgánica, depositada entre ellos.

Las excavaciones han puesto al descubierto una compleja y bien planificada organización del espacio, tanto al nivel de las unidades de habitación, separadas por calles, como de su interior, observándose asimismo evidentes diferencias entre los grupos de casas y en cada una de ellas. No obstante, en las excavaciones recientes no hemos constatado significativas modificaciones en la arquitectura exterior que permanece en pie durante la vida del poblado, aunque en la última campaña hemos detectado una intrusión a modo de gran mancha de tierras oscuras con restos arquitectónicos de barro y yeso y algunos materiales arqueológicos que corta la capa estéril de yeso que sella el poblado, cuya excavación abordaremos en la campaña de 1998.

Son muchos los elementos culturales que podríamos destacar de estos niveles del Cabezo Redondo. A nivel de las cerámicas sobresale el progresivo aumento, siempre en una pequeña proporción sobre el cómputo global, de las cerámicas decoradas, los cada vez más numerosos cuencos y cazuelas con la carena en el tercio superior, los tratamientos bruñidos y la calidad de las pastas de algunos recipientes, los ónfalos, los vasos geminados y los recipientes cubiertos de mamelones. No menor interés tienen las pesas de telar cilíndricas con una perforación, algún tipo de punzón y de puntas de flecha de hueso y las puntas de flecha de metal con pedúnculo, aletas y punta redondeada realizada en una delgada lámina de bronce. Son algunos de estos elementos los que nos han permitido clasificar dentro del Bronce Tardío a otros yacimientos alicantinos. Especial interés tienen los enterramientos publicados por J. M ${ }^{a}$ Soler que, conjuntamente con los descubiertos en las recientes excavaciones debe relacionarse por su posición estratigráfica o sus ajuares con este Bronce Tardío para los que se ha señalado que responden a «normas funerarias argáricas, aunque reinterpretadas" (Jover Maestre y López Padilla, 1997). En este mismo sentido los tres enterramientos - un adulto en cista y dos infantiles en cuencos, uno de ellos con la boca tapada con otra vasijadel Mas del Corral también se han relacionado con niveles del Bronce Tardío (Trelis, 1992: 87).

Como hemos señalado en otra ocasión por la complejidad de su arquitectura, dimensiones y variedad y riqueza de sus ajuares el Cabezo Redondo es el yacimiento que articula todo el poblamiento de la segunda mitad del II milenio cal ANE del sur de las tierras valencianas. Su despegue coincide con los indicios de crisis social para el mundo argárico (Lull y Risch, 1995), en cuya periferia se ubica. Una fértil agricultura, la abun- 
dancia de ganado, el control de salinas, su situación estratégica en vías de paso y control y su proximidad al mar explicaría su desarrollo e, incluso, la presencia de esa singular acumulación de objetos de oro y plata que constituye el Tesoro de Villena, el Tesorillo del Cabezo Redondo y, lo que nos parece más signiticativo, los propios objetos de oro, en especial los conos, que con una regularidad sorprendente aparecen en los niveles de habitación y en los enterramientos en estos mismos niveles. El Tesoro de Villena pertenece, indudablemente, a un personaje preminente que habita en el Cabezo Redondo y que tiene el suficiente poder para recibir, comprar o heredar este excepcional conjunto de orfebrería de oro y plata, en el que podría existir un cetro (Hernández Pérez, 1997).

En los yacimientos castellonenses con dataciones absolutas en este tramo cronológico propuesto para el Bronce Tardío en el sudeste no se conocen cerámicas con decoración tipo Cogotas I, aunque en estas tierras del País Valenciano se registraran los más antiguos hallazgos. Es el caso de El Castellet (Esteve, 1944), con claros paralelos en la Meseta central y Álava (Delibes de Castro y Abarquero Moras, 1997: 122).

Del exigüo registro de materiales publicados pertenecientes a los niveles datados en estos yacimientos de Castellón destacaríamos los pertenecientes al Torrelló de Onda (figura 6) con varios recipientes carenados, uno de ellos con ónfalo, y una punta de hueso de tres aristas y doble línea de rudimentarias aletas próxima a otras del Bronce Tardío del Cabezo Redondo. También cerámicas carenadas y una de ellas con ónfalo se señalan para el Nivel I de Mas d'Abad (figura 3), indicándose, asimismo, que ambos elementos estan ausentes en el Nivel II del mismo yacimiento (figura 4). Por otro lado, de los niveles datados de Orpesa la Vella se citan sólo cuatro fragmentos cerámicos con decoración en su cuerpo, de los que se publica uno (figura 7) con tres líneas verticales de puntillado. Para este yacimiento se señala que las cerámicas del Nivel IV, donde se obtuvieron las dataciones, son similares a las del Nivel III, destacando en ambos la abundante cerámica carenada, la calidad de las pastas y, lo que resulta más significativo, la ausencia de los vasos geminados unidos por doble puente, que en las tierras meridionales se asocian al Bronce Tardío, y que en Orpesa se registran en su fase $A$, que sus excavadores fechan entre el 1200-900 arq. ANE.

La documentación disponible no permite precisar los elementos culturales que podrían considerarse característicos de este momento, por cuanto algunos de ellos como las cerámicas carenadas o los ónfalos también los encontramos en yacimientos con cronologías calibradas del Bronce Final. El ejemplo más evidente lo constituyen las cerámicas del Nivel I de 
Mas d'Abad, donde se registran recipientes carenados y ónfalos, no presentes en el nivel infrapuesto. Es este sentido conviene recordar la opinión de los excavadores del Abric de les Cinc cuando señalan que la cerámica del Bronce Final en Castellón «no posee una ruptura apreciable tanto en los aspectos formales como constitutivos, perviviendo fuertemente la tradición alfarera del Bronce Tardía» (Junyent et alii, 1982/1983: 102). De este modo, creemos que algunos de los yacimientos castellonenses tradicionalmente relacionados con el Bronce Final podrían integrarse en una nueva fase de la Edad del Bronce que se iniciaría hacia el siglo XVI cal ANE, delimitado en su tramo inicial por las dataciones de Can Ballester y El Torrelló de Onda, y perduraría hasta la incorporación, en ocasiones en los mismos poblados al aire libre o en cuevas ocupadas con anterioridad, de elementos de los Campos de Urnas. Son estos elementos, junto a la aparición de nuevos lugares de hábitat, cuyo paradigma es Vinarragell (Mesado Oliver y Arteaga Matute, 1979), los que marcarían el inicio del Bronce Final. A la espera de concluir el estudio que preparamos sobre la segunda mitad del II milenio a.C. en el País Valenciano, no creemos conveniente introducir una nueva «etiqueta» para ese tramo de más de seis siglos en la Prehistoria Reciente de Castellón. No somos partidarios de emplear el de Bronce Tardío, por cuanto éste implica unas características que no parecen encontrarse en los yacimientos. No obstante, la anunciada publicación del excepcional yacimiento de Orpesa la Vella posiblemente permitan establecer las características de esta fase y, lo no sería descartable, una subdivisión interna.

Para las comarcas centrales no disponemos de dataciones absolutas posteriores a la del Pic de les Corbs, por lo que cualquier propuesta debe apoyarse en el estudio de las estratigrafías de los yacimientos excavados, entre los que destacamos la Lloma de Betxí y Muntanya Assolada, en las cuencas del Túria-Júcar, y en los paralelos de sus materiales y los de otros yacimientos procedentes de actuaciones de diverso tipo, pero casi siempre descontextualizados. En el riguroso análisis de $\mathrm{B}$. Martí y $\mathrm{M}^{\mathrm{a}} \mathrm{J}$. de Pedro (1997) se ofrece, junto a una excelente parte gráfica, un avance de las excavaciones de esos dos poblados y una información excepcional sobre la organización del hábitat en sus entornos. La presencia de cerámicas decoradas con cordones, incisiones o mamelones que cubren toda la pared, la abundancia de recipientes carenados, algunos con ónfalos y decorados y los vasos geminados, entre otros elementos, remiten a paralelos septentrionales y meridionales reinterpretados que permitir adivinar, siempre sobre la información actualmente disponible, una facies propia que difícilmente podemos acotar en el tiempo, aunque las fechas disponibles para los momentos anteriores y sus paralelos en el mismo territorio 
valenciano sugieren una cronología similar a la propuesta para Castellón y que aquí, como allí, la próxima publicación de los resultados de las excavaciones en la Lloma de Betxí, Montanya Assolada y Pics de la Corbs o el detenido estudio de materiales, del que es buen ejemplo el realizado sobre La Peladilla de Requena (Barrachina, 1992) o el castellonense de Ereta del Castellar (Ripollés Adelantado, 1997), permitirán, sin duda, evaluar las influencias y, quizas establecer una periodización interna. La presencia de cerámicas tipo Cogotas en La Peladilla y de algún recipiente con la carena en las proximidades del borde no son, en nuestra opinión, indicios suficientes para utilizar el término de Bronce Tardío por las implicaciones antes aludidas.

El Bronce Tardío es, por tanto, un término que sólo tiene validez en las comarcas meridionales, en lo que podríamos denominar la perifería de El Argar que consideramos rebasa el Vinalopó para incorporar yacimientos de la zona norte de Alicante, como la llleta dels Banyets, Mas del Corral o Camp Prim. Es cierto que el número de fragmentos cerámicos tipo Cogotas I, pese al aumento en el registro, sigue siendo bajo y de amplia cronología, según la sistematización meseteña, por lo que consideramos que deben ser otros los elementos que caractericen esa fase. El Cabezo Redondo es, sin duda, el paradigma del yacimiento del Bronce Tardío en esta zona. El análisis de sus materiales nos revela que debe relacionarse con el Tesoro de Villena, con todo lo que ello implica a nivel económico y social, y que perdura hasta que las influencias septentrionales - cerámicas de Campos de Urnas desde Mola d'Agres (Peña et alii, 1996) a Saladares (Arteaga y Serna, 1979-80) - meridionales desde la cerámica con incrustaciones metálicas de Mola d'Agres (Lucas, 1995) o Caramoro II (González Prats y Ruiz Segura, 1992) a las cerámicas finas de Peña Negra I (González Prats 1985 y 1990 o Saladares (Arteaga y Serna, 1979-80)-, mediterráneas —elementos del propio Tesoro de Villena (Ruiz-Gálvez, 1992 y 1995) o la fíbula «ad occhio» de Mola de Agres (Gil Mascarell y Peña 1989) - y atlánticas -elementos del Tesoro (Ruiz-Gálvez, 1992 y 1995) y metalurgia de Peña Negra (González Prats, 1992 b)- marcan el inicio del Bronce Final con la aparición de nuevos poblados - Peña Negra, Saladares, ...-, o se reubique el hábitat en otros -Mola de Agres, Tabayá, ...-. Somos conscientes de que la clave para explicar muchos de los problemas que hemos planteado en las páginas anteriores se encuentran en yacimientos que hemos tenido ocasión de excavar y cuyas memorias de excavación esperamos publicar el próximo año, cuando se cumplen 35 años de que $M$. Tarradell afirmara que "este trabajo no nos hubiera sido resultado posible a no ser por las múltiples ayudas obtenidas de los colegas que llevan investigando 
en el país muchos más años que nosotros». 35 años después me apropio de sus palabras.

\section{BIBLIOGRAFÍA}

Alcácer Grau, J., 1945: «Dos estaciones argáricas de la Región Levantina». Archivo de Prehistoria Levantina, II, pp. 151-163. Valencia.

Almagro Gorbea, M., 1977: «El Pic dels Corbs de Sagunto y los Campos de Urnas del NE de la Península lbérica". Saguntum, 12, pp. 89-144. Valencia.

ARteaga, O., 1981: «Problemas de la Protohistoria de la Península lbérica». Boletín de la Asociación Española de Amigos de la Arqueología», 14, pp. 4-16. Madrid.

ARTEAGA, O. y Serna, Ma R., 1979-80: «Las primeras fases del poblado de Los Saladares (Orihuela-Alicante). Una contribución al estudio del Bronce Final en la Península Ibérica (Estudio crítico 1)». Ampurias, 41-42, pp. 65-137. Barcelona.

BarRachinA, A., 1989: «Breve avance sobre el estudio del poblado del Pic de les Corbs". En Homenatge A. Chabret 1888-1988, pp. 31-42. Valencia.

- 1992: "El yacimiento de la Edad del Bronce de La Peladilla (Requena, Valencia)». Saguntum, 25, pp. 69-83. Valencia.

Bernabeu, J., Guitart, I. y PAscual-Benito, J., 1989: «Reflexiones sobre el patrón de asentamiento en el País Valenciano desde el Neolítico a la Edad del Bronce». Saguntum, 22, pp. 81-124. Valencia.

Clausell Cantavella, G., 1995: «Nuevos hallazgos fenicios en provincia de Castellón». Quaderns de Prehistòria i Arqueologia de Castelló, 16, pp. 93-106. Castellón.

- 1997: «Materiales del Bronce Medio del Boverot d'Almassora (Castellón)». La Murà, 1, pp. 21-30. Almassora.

Colominas Roca, J., 1925: “Noticies. La necrópolis argárica de Callosa (provincia d'Alacant)». Bulleti de l'Associació Catalana d'Antropologia, Etnologia i Prehistòria, III, pp. 111-113. Barcelona.

- 1927: «La necrópolis de 'Las Laderas del Castillo' (Callosa del Segura, provincia d'Alacant)". Anuari del Institut d'Estudis Catalans, XXXI, pp. 33-61. Barcelona.

- 1931: «Crònica d'Arqueologia i Història de l'Art, Edat del Bronze. La necrópolis de 'Las Laderas del Castillo' (Callosa de Segura, provincia d'Alacant)". Anuari de l'Institut d'Estudis Catalans, pp. 33-39. Barcelona.

De Pedro Micho, J., 1990: "La Lloma de Betxí (Paterna): datos sobre las técnicas de construcción de la Edad del Bronce». Archivo de Prehistoria Levantina, XX, pp. 327-350. Valencia.

- 1995: «La Edad del Bronce en el País Valenciano: estado de la cuestión». Actes de les Jornades d'Arqueología. Alfàs del Pi del 27 al 29 de gener de 1994, pp. 61-87. Valencia.

Delibes de CAstro, G. y ABARquero Moras, F.J., 1997: "La presencia de Cogotas I en el País Valenciano: acotaciones al tema desde una perspectiva meseteña». Saguntum, 30 , pp. 115-134. Valencia.

Enguix, R. y MARTí, B., 1988: «La Cultura del Bronce Valenciano y la Muntanya Assolada de Alzira. Aproximación al estado actual de la investigación». Archivo de Prehistoria Levantina, XVIII, pp. 241-250. Valencia.

Esteve Gálvez, F., 1944: “Un poblado de la Edad del Hierro en la Plana de Castellón». Ampurias, VI, pp. 141-154. Barcelona.

FLETCHER, D., 1953: "Avances y problemas de Prehistoria valenciana en los últimos veinticinco años». Anales del Centro de Cultura Valenciana, XXI, pp. 8-36. Valencia.

Gil-MascarelL, M., 1981: "El Bronce Tardío y el Bronce Final en el País Valenciano». El Bronce Final y el comienzo de la Edad del Hierro en el Pais Valenciano, pp. 9-39. Valencia.

- 1985: "El final de la Edad del Bronce». Arqueología del País Valenciano: panorama y perspectivas, pp. 141-152.

- 1992: «La agricultura y la ganadería como vectores económicos del desarrollo del Bronce Valenciano". Saguntum, 25, pp. 49-67. Valencia.

- 1995: "Algunas reflexiones sobre el Bronce Valenciano». Saguntum, 28, pp. 63-74. Valencia. 
Gil-MASCARell, M. y Enguix, R., 1986: "La Cultura del Bronce Valenciano: estado actual de la investigación”. Homenaje a Luis Siret (1934-1984), pp. 418-454. Sevilla.

Gil-Mascarell, M. y EnRiQue TeJedo, M., 1992: «La metalurgia del Bronce Final-Hierro Antiguo del yacimiento de la Mola d'Agres (Agres, Alicante). Trabajos Varios del S.I.P., 89, pp. 3950. Valencia.

Gil-Mascareil, M. y Peña SÁnchez, J.L., 1989: "La fíbula: "ad occhio" del yacimiento de la Mola d'Agres". Saguntum, 22, pp. 125-146. Valencia.

GONZÁlez, P., 1994: “Cronología del grupo argárico». Revista d'Arqueología de Ponent, 4, pp. 7-46.

Gonzalez Prats, A., 1979 Excavaciones en el yacimiento protohistórico de La Peña Negra, Crevillente (Alicante). (1 $1^{a}$ y $2^{a}$ campañas). Madrid.

- 1983 Estudio arqueológico del poblamiento antiguo de la Sierra de Crevillente (Alicante). Alicante.

- 1985: «La Peña Negra, II-III. Campañas de 1978 y 1979». Noticiario Arqueológico Hispánico, 21, pp. 9-155. Madrid.

- 1986 a: «El poblado calcolítico de les Moreres en la Sierra de Crevillente, Alicante». El Eneolítico en el País Valenciano, pp.89-110. Alicante.

- 1986 b: «La Peña Negra V. Excavaciones en el poblado del Bronce Antiguo y en el recinto fortificado ibérico (Campaña de 1982)». Noticiario Arqueológico Hispánico, 27, pp. 143-263. Madrid.

- 1990 Nueva luz sobre la Protohistoria del Sudeste. Alicante.

- 1992 a: «El proceso de formación de los pueblos ibéricos en el Levante y Sudeste de la Península lbérica». Complutum, 2-3, pp. 13-150. Madrid.

- 1992 b: «Una vivienda metalúrgica en La Peña Negra (Crevillente-Alicante). Aportación al conocimiento del Bronce Atlántico en la Península Ibérica». Trabajos de Prehistoria, 49, pp. 243-257. Madrid.

González Prats, A. y Ruiz Segura, E., 1991-1992: «Nuevos datos sobre el poblado calcolítico de Les Moreres, Crevillente (Alicante). (Campañas 1988-1993)". Anales de Prehistoria y Arqueología, 7-8, pp. 17-20. Murcia.

- 1992: «Un poblado fortificado del Bronce Final en el Bajo Vinalopó». Trabajos Varios del S.I.P., 89, pp. 17-27. Valencia.

- 1995: «Urbanismo defensivo de la Edad del Bronce en el Bajo Vinalopó. La fortificación argárica de Caramoro I (Elche, Alicante)». Estudios de vida urbana, pp. 85-107. Murcia.

Gusi Jener, F., 1975: «Las dataciones del C-14 de la Cueva de Mas d'Abad (Coves de Vinromá). Campaña 1975. Ensayo cronológico para la periodización del Bronce Valenciano". Cuadernos de Prehistoria y Arqueología Castellonenses, 2, pp. 75-79.

- 1979: «El poblado de la Edad del Bronce de Orpesa la Vella (Orpesa del Mar, Castellón)». Cuadernos de Prehistoria y Arqueología Castellonenses, 4, pp. 79-100. Castellón.

- 1989: "Problemática actual en la investigación de la Edad del Bronce en el País Valenciano". XIX Congreso Nacional de Arqueología. Ponencias y comunicaciones. Vol. I, pp. 239-249.

GuSI JENER, F. y OlÁRIA PuYOLES, C., 1977: «La cerámica de la Edad del Bronce de la Cueva de Mas d'Abad. Campaña arqueológica 1975», Cuadernos de Prehistoria y Arqueología castellonense, 3, pp. 103-115. Castellón.

- 1992: "Cronologies absolutes en l'Arqueo'ogia del País Valencià". Actes de les Jomades d'Arqueologia. Alfàs del Pi del 27 al 29 de gener de 1994, pp. 119-157. Valencia.

HernÁndez Pérez, M.S., 1985: "La Edad del Bronce en el País Valenciano: panorama y perspectivas». Arqueología en el País Valenciano. Panorama y perspectivas, pp. 101-119. Alicante.

- 1986: "La Cultura de El Argar en Alicante. Relaciones temporales y espaciales con el mundo del Bronce Valenciano". Homenaje a L. Siret, pp. 321-350. Sevilla.

- 1990: «Un enterramiento argárico en Alicante». Homenaje a Jerónimo Molina, pp. 87-94. Murcia.

- 1997: «Desde la Periferia de El Argar. La Edad del Bronce en las tierras meridionales valencianas». Saguntum, 30, pp. 93-114. Valencia.

Hernandez Pérez, M.S. y López Mira, J.A., 1992: «Bronce Final en el Medio Vinalopó. A propósito de dos conjuntos cerámicos del Tabaià (Aspe, Alicante)". Trabajos Varios del S.I.P., 89, pp. 1-16. Valencia.

Jover Maestre, J.F., López Mira, J.A. y López PADilla, J.A., 1995 el poblamiento durante el II milenio a.C. en Villena (Alicante). Alicante. 
Jover Maestre, F.J. y López Padilla, J.A., 1997 Arqueología de la muerte. Prácticas funerarias en los límites de El Argar. Alicante.

Jover MAestre, F.J. y Segura Herrero, G., 1995 El poblamiento antiguo en Petrer. De la Prehistoria a la Romanidad Tardía. Petrer.

JUNYENT, E. et alii, 1982/1983: «El Abric de Les Cinc (Almenara, Castellón). $2^{2}$ Campaña de excavaciones 1977". Cuadernos de Prehistoria y Arqueologia Castellonenes, 9, pp. 55-121. Castellón.

Llobregat, E.A., 1969: «El poblado de la Cultura del Bronce Valenciano de la Serra Grossa, Alicante». Papeles del Laboratorio de Arqueología de Valencia, 6, pp. 31-70. Valencia.

- 1971: «Eine siedlung des 'Bronce valenciano' auf der Serra Grossa (Prov. Alicante)». Madrider Mitteilungen, 12, pp. 87-100. Heildelberg.

LULL, V., 1983 La "cultura" de El Argar. (Un modelo para el estudio de las formaciones económico-sociales prehistóricas). Madrid.

LUL., V. y RISCH, R., 1995: «El estado argárico». Verdolay, 7, pp. 97-109. Murcia.

MarTí Oliver, B., 1983 El nacimiento de la agricultura en el País Valenciano. Del Neolítico a la Edad del Bronce. Valencia.

Marti Oliver, B. y Bernabeu, J., 1992: "La Edad del Bronce en el País Valenciano». Aragón/Litoral mediterráneo. Intercambios culturales durante la Prehistoria, pp. 555-567. Zaragoza.

Martí Oliver, B. y De Pedro Michó, Ma J., 1995: «Los poblados de la Cultura del Bronce Valenciano: Modelo tradicional y nuevas excavaciones". Extremadura Arqueológica, pp. 101-114. Cáceres.

- 1997: "Sobre el final de la Cultura del Bronce Valenciano: problemas y progresos". Saguntum, 30, pp. 59-91. Valencia.

Mata Parreño, C., Marti Bonafé, Mª A. e Iborra Eres, Mª P., 1994/96: “El País Valencià del Bronze Recent a l'lbèric Antic: el procés de formació de la societat urbana ibèrica". Gala, 35, pp. 183-218. Gerona.

MESADO, N. y ARTEAGA, O., 1979 Vinarragell (Burriana-Castellón). Valencia.

MOLINA, F., 1978: «Definición y sistematización del Bronce Tardío y Final en el Sudeste de la

- Península Ibérica». Cuadernos de Prehistoria de la Universidad de Granada, 1, pp. 159-232. Granada.

Moreno Tovillas, S., 1942 Apuntes sobre las estaciones prehistóricas de la Sierra de Orihuela. Valencia.

Navarro Mederos, J.F., 1982: "Materiales para el estudio de la Edad del Bronce en el Valle Medio del Vinalopó (Alicante)». Lucentum, I, pp. 19-70. Alicante.

- 1986: «La Lloma Redona». Arqueología en Alicante, 1976-1986, pp. 102-103. Alicante.

- 1987: "Lloma Redona. Monforte del Cid, Vinalopó Mitjà. Memóries arqueològiques a la Comunitat Valenciana, 1984-1985, pp. 79-81. Valencia.

Nieto Gallo, G., 1959: "Objetos del Bronce II de la Necrópolis de San Antón, Orihuela (Alicante)". Revista de Archivos, Bibliotecas y Museos, LXVIII, 1, pp. 299-317. Madrid.

OlARIA, C., 1977: "Las dataciones del C-14 en el País Valenciano". Cuadernos de Prehistoria y Arqueología Castellonenses, 4, pp. 271-280. Castellón.

- 1987: «Un poblado del Bronce a orillas del mar. Orpesa la Vella, Castellón. Revista de Arqueología, 78, pp. 15-19. Madrid.

OLARIA, C. y GUSI, F., 1976: "Un asentamiento en cueva de la Edad del Bronce, el Forat de Cantallops (Ares del Maestre, Castellón». Cuadernos de Prehistoria y Arqueología Castellonenses, 3, pp. 133-150. Castellón.

Palomar, V., 1986: "La Cueva del Murciélago (Altura-Castellón). $1^{\text {a }}$ y $2^{\mathrm{a}}$ campaña de excavaciones». Cuadernos de Prehistoria y Arqueologia Castellonenses, 12, pp. 45-95.

- 1990/91: "Las dataciones de C-14 de la Cueva del Murciélago (Altura, el Alto Palancia)". Cuadernos de Prehistoria y Arqueología Castellonenses, 15, pp. 437-442.

- 1995 La Edad del Bronce en el Alto Falancia. Segorbe.

PEÑA, J.L. et alii, 1996 El poblado de la Mola d'Agres. Valencia.

Pla Ballester, E., 1958: "La covacha de Ribera (Cullera, Valencia). Archivo de Prehistoria Levantina, VIII. Valencia.

Ramos Fernández, R., 1981: “El Promotorio del Aigua Dolça i Salà de Elche. Avance a su estudio». Archivo de Prehistoria Levantina, XVI, pp. 197-222. Valencia.

- 1988: “Caramoro: una fortaleza vigía de la Edad del Bronce». Homenaje a Samuel de los Santos, pp. 197-222. Albacete. 
ROMÁN LAJARín, J.L., 1975: "Un yacimiento de la Edad del Bronce en el Pic de les Moreres (Crevillente, Alicante)". Archivo de Prehistoria Levantina, XIV, pp. 47-63. Valencia.

- 1980: «Los yacimientos de la Edad del Bronce de la Serra del Buho». Festa d'Elig, pp. 3956. Elche.

Rovira Llorens, S., Montero Ruiz, I. y Consuegra Rodríguez, S., 1997 Las primeras etapas metalúrgicas en la Península lbérica. I. Análisis de materiales. Madrid.

RIPOLLÉS ADELANTADO, E., 1997: «La Ereta de Castellar (Villatranca): Avance a la revisión de un yacimiento del Bronce Valenciano». Archivo de Prehistoria Levantina, XXII, pp. 157-178. Valencia.

Rubio de LA Serna, J., 1907: «El Museo Arqueológico de Santo Domingo de Orihuela», pp. 361-444. Barcelona.

Ruiz-GÁlvez Priego, M., 1992: «La novia vendida: orfebrería, herencia y agricultura en el Protohistoria de la Península lbérica». Spal, 1, pp. 219-251. Sevilla.

- 1995 Ritos de paso y Puntos de paso. La Ría de Huelva en el mundo del Bronce Final europeo. Madrid.

Ruiz SegurA, E., 1990: «El fenómeno campaniforme en la provincia de Alicante». Ayudas a Investigación 1986-1987 del Instituto de Cultura Juan Gil-Albert, V.III, pp. 71-81.

RuIz ZaPATERO, G., 1981: «Las penetraciones de Campos de Urnas en el País Valenciano». Cuadernos de Prehistoria y Arqueología Castellonenses, 5, pp. 243-255. Castellón.

Simón García, J.L., 1995 Los orígenes de la metalurgia en el País Valenciano. Tesis Doctoral inédita. Universidad de Alicante.

- 1997: «La llleta: asentamiento litoral en el Mediterrábeo occidental de la Edad del Bronce». La llleta dels Banyets (El Campello, Alicante). Estudios de la Edad del Bronce y época Ibérica, pp. 47-132. Alicante.

SIRET, E., 1905: «Note sur le communication du R. P. Furgús relative a des tombes préhistoriques a Orihuela». Annales de la Societé d'Archéologie de Bruxelles, XIX, pp. 371-380. Bruselas.

SIRET, E. y L., 1890: Las primeras edades del metal en el Sudeste de España. Barcelona.

SOLER DÍAZ, J., 1995: «Algunas consideraciones en torno al campaniforme en la provincia de Alicante". Actas del XXII Congreso Nacional de Arqueología, vol. II, pp. 11-16. Vigo.

Soler García, J.Ma 1965 El Tesoro de Villena. Madrid.

- 1981 El Eneolítico en Villena. Valencia.

- 1987 Excavaciones arqueológicas en el Cabezo Redondo (Villena, Alicante). Alicante.

- 1989 Guía de los yacimientos y del Museo de Villena. Valencia.

Soler García, J.M y y Fernández Moscoso, E., 1970: «Terlinques, poblado de la Edad del Bronce en Villena». Papeles del Laboratorio de Arqueología de Valencia, 10, pp. 27-62. Valencia.

SORIANO SÁNCHEZ, R., 1984: «La cultura de El Argar en la Vega Baja del Segura». Saguntum, 19, pp. 103-143. Valencia.

- 1985: «Contribución al estudio del Bronce Tardío y Final en la Vega Baja del Segura». Saguntum, 19, pp.107-129. Valencia.

- 1989 Contribución a la Prehistoria e Historia Antigua de Callosa del Segura (Alicante). Callosa del Segura.

TARRADELL, M., 1947: «Sobre la delimitación geográfica de la Cultura del Argar». Crónica del /I Congreso Arqueológico del Sudeste Español (Albacete, 1946), pp. 139-145. Cartagena.

- 1950: «La Península Ibérica en la época del Argar». V Congreso Arqueológico del Sudeste Español (Alcoy, 1949), pp. 72-85. Cartagena.

- 1963 El País Valenciano del Neolítico a la Iberización. Ensayo de sintesis. Valencia.

- 1969: "La Cultura del Bronce Valenciano. Nuevo ensayo de aproximación». Papeles del Laboratorio de Arqueología de Valencia, 6, pp. 8-30. Valencia.

- 1970: «Dos nuevas fechas de C-14 para Villena y Mallorca». Papeles del Laboratorio de Arqueología de Valencia, 10, pp. 19-26. Valencia.

Trelis Martí, J., 1992: «Excavaciones en el yacimiento de la Edad del Bronce de Mas del Corral (Alcoy-Alicante)". Recerques del Museu d'Alcoi, l, pp. 85-89. Alcoy.

VIÑAS, R., CAMPIllo, D. y MIQUel, D., 1976: "La cueva de Mas d'Abad (Coves de Vinromá), Castellón. Campaña Arqueológica, 1975)\%. Cuadernos de Prehistoria y Arqueología Castellonenses, 3, pp. 81-102.

WALKER, M.J., 1981: «El yacimiento prehistórico de Catí-Foradà (Petrel-Alicante)». Instituto de Estudios Alicantinos, 32, pp. 87-89. Alicante. 